\title{
Retrospective mercury exposure and current symptoms of nervous system dysfunction in adults of a First Nation community (Canada)
}

\section{Aline Philibert}

Universite du Quebec a Montreal

Myriam Fillion

TÉLUQ University

Judy Da Silva

Grassy Narrows First Nation

Tanya Suvendrini Lena

Women's College Hospital

Donna Mergler ( $\nabla$ mergler.donna@uqam.ca )

Universite du Quebec a Montreal https://orcid.org/0000-0002-5205-5180

\section{Research}

Keywords: mercury, past exposure, First Nation, nervous system dysfunction, symptom clusters, clustering, structural equation modelling, mixed effects model

Posted Date: October 18th, 2021

DOI: https://doi.org/10.21203/rs.3.rs-952530/v1

License: (c) (i) This work is licensed under a Creative Commons Attribution 4.0 International License. Read Full License 
1 Retrospective mercury exposure and current symptoms of nervous system dysfunction in adults of a First Nation community (Canada)

3 Aline Philibert ${ }^{(1)}$, Myriam Fillion ${ }^{(2,1)}$, Judy Da Silva ${ }^{(3)}$, Tanya Suvendrini Lena ${ }^{(4)}$, Donna

$4 \quad$ Mergler $^{(1)}$

5 (1) Université du Québec à Montréal, Centre de recherche interdisciplinaire sur le bien-être, la

6 santé, la société et l'environnement (Cinbiose), CP 8888, Succ. Centreville, Montréal, Québec,

7 Canada, H3C 3P8

8 (2) Département Science et Technologie, Université TÉLUQ, 5800 Saint Denis St, Montréal,

9 Québec, Canada H2S 3L4

10 (3) Grassy Narrows First Nation, General Delivery, Grassy Narrows, Ontario, Canada

11 P0X 1B0

$12{ }^{(4)}$ Women's College Hospital 76 Grenville St, Toronto, Ontario, Canada M5S 1B2

13

14

15 corresponding author:

16 Donna Mergler

17 mergler.donna@uqam.ca

18

19 CINBIOSE

20 Université du Québec à Montréal

21 CP 8888, succ Centreville

22 Montréal, Québec

23 Canada H3C 3P8 


\section{Abstract}

27 Background: The watershed in Asubpeeschoseewagong Netum Anishinabek (Grassy Narrows

28 First Nation) territory has been contaminated by mercury (Hg) since 1962, resulting in very high

$29 \mathrm{Hg}$ concentrations in fish, central to the community's culture, traditions, economy and diet.

30 Biomarkers of $\mathrm{Hg}$ (umbilical cord blood and hair/blood samples), monitored between 1970 and

31 1997, decreased over time. A recent Grassy Narrows Community Health Assessment (GN-CHA)

32 survey included current symptoms of nervous system dysfunction. The present study aimed to

33 cluster self-reported symptoms and examine their relation to past $\mathrm{Hg}$ exposure.

35 Methods: The GN-CHA included 391 Registered adult Band members. Symptom clustering used

36 a two-step segmentation approach. Umbilical cord $\mathrm{Hg}$ and yearly measurements of hair $\mathrm{Hg}$ were

37 available for 242 participants. Longitudinal Mixed Effects Models (LMEM) served to examine

38 past hair $\mathrm{Hg}$ with respect to clusters. Structural Equation Models (SEM) displayed direct and

39 indirect pathways between $\mathrm{Hg}$ exposure and clusters, with $\mathrm{Hg}$ exposure modelled as a latent

40 variable or in separate time periods (prenatal, childhood and having had hair $\mathrm{Hg} \geq 5 \mu \mathrm{g} / \mathrm{g}$ at least

41 once).

43 Results: A total of 37 symptoms bonded into 6 clusters, representing Extrapyramidal impairment,

44 Sensory impairment, Cranial nerve disturbances, Gross motor impairment, Neuro-cognitive

45 deficits and Affect/Mood disorders. Median Hg concentrations were $5 \mu \mathrm{g} / \mathrm{L}(1-78.5)$ and $1.1 \mu \mathrm{g} / \mathrm{g}$

46 (0.2-16) for umbilical cord and childhood hair, respectively. More than one-third (36.6\%) had hair

$47 \mathrm{Hg} \geq 5 \mu \mathrm{g} / \mathrm{g}$ at least once. LMEM shows higher long-term hair Hg among those with higher scores 
48 for most clusters. In SEM, latent $\mathrm{Hg}$ is directly and indirectly associated with all clusters. The

49 contribution of prenatal exposure is mediated by childhood exposure, except for Affect/Mood

50 disorders, where the association is direct. Hair $\mathrm{Hg} \geq 5 \mu \mathrm{g} / \mathrm{g}$ is directly related to Extrapyramidal

51 and Sensory impairment.

52

53 Conclusion: Our findings provide evidence that in this First Nation community, past Hg exposure

54 from fish consumption was associated with later-life clusters of coexisting symptoms of nervous

55 system dysfunction. Given the complexity of the interrelations between the various determinants

56 of chronic health problems in this and other First Nation communities, LMEM and SEM methods

57 provide the opportunity to trace direct and/or indirect effect routes of potential "causal impact".

60 Keywords: mercury, past exposure, First Nation, nervous system dysfunction, symptom clusters, 61 clustering, structural equation modelling, mixed effects model

62 


\section{Background}

65 In the 1960's, a chloralkali plant discharged approximately 10,000 $\mathrm{kg}$ of mercury $(\mathrm{Hg})$ into the

66 Wabigoon-English River system in Northwestern Ontario, contaminating fish resources as far as

$67250 \mathrm{~km}$ downstream (1). Asubpeeschoseewagong Netum Anishinabek (Grassy Narrows First

68 Nation) and Wabaseemoong Independent Nation (previously known as Whitedog and Islington

69 Bands), for whom walleye (Sander vitreus) is central to their traditions, culture, economy and

70 health, were seriously affected by this disaster (2). Between 1970 and 1997, governmental

71 agencies carried out biomonitoring programs in these communities to assess $\mathrm{Hg}$ concentrations in

72 blood and hair (3). Another program (1970-1992) assessed Hg concentrations in umbilical cord

73 bloods collected at the local hospital $(3,4)$. Biomarker Hg concentrations from Grassy Narrows

74 First Nation followed a similar pattern to $\mathrm{Hg}$ levels in local fish from the contaminated river

75 system, with extremely high concentrations in the early 1970's, a sharp decline until 1977 and a

76 less pronounced decline until 1987, after which, mean concentrations remained relatively stable $77(5,6)$.

79 In 1975, neurological examinations of 89 residents from the two communities, carried out by Dr.

80 Masazumi Harada and colleagues (7), showed a high prevalence of signs and symptoms similar to

81 those reported by patients with Minamata Disease. The team revisited the communities in 2002

82 and 2004 and examined 175 individuals. Sixty (60) persons were diagnosed with Minamata

83 Disease, 54 with Minamata Disease with complications due to other diseases, and 25 with

84 "suspicion of Minamata Disease" (7). Self-reported symptoms included numbness, pain in limbs,

85 joints and back, decreased vision, impaired hearing, cramps in limbs, dizziness, tendency to fall, 
86 forgetfulness, impaired finger movement, tremor and speech impairment. For 27 persons who had

87 been examined in 1975, symptoms had worsened (7). Takaoka and co-authors (8) compared self-

88 reported symptoms of volunteers from the Grassy Narrows First Nation community from

89 examinations performed in 2010, with residents from the Minamata area and a reference group

90 from other areas of Japan. The authors observed that the prevalence of specific and non-specific

91 complaints of older persons from Grassy Narrows was similar to that of those from the Minamata

92 area, while the prevalence among younger persons from Grassy Narrows was lower, but higher

93 than the Japanese reference group (8). While signs and symptoms reported in this study are

94 consistent with methylmercury poisoning (9), the findings are limited by the recruitment strategy

95 and the absence of measurements of mercury exposure.

97 In 2015, Grassy Narrows First Nation undertook a Community Health Assessment survey (GN-

98 CHA), which included a list of 59 symptoms, as well as questions on current and past fish

99 consumption. Although understanding one single symptom is worthwhile per se, people rarely

100 present with one single symptom, but rather with an array of multiple coexisting symptoms (10).

101 Symptom clusters represent a group of two or more related concurrently occurring symptoms (10),

102 whose pattern reflects the nature of the underlying dysfunction (11). New multidimensional

103 approaches and statistical techniques have been proposed to facilitate the integrated analysis of

104 multiple symptoms $(10,12-15)$. Over the same period, a growing body of research has used

105 advanced statistical techniques to examine the contributions of $\mathrm{Hg}$ exposure (16-26). The objective

106 of the present study was to bond GN-CHA reported symptoms of nervous system dysfunction into

107 clusters and to examine their association to long-term and past $\mathrm{Hg}$ exposure. 
111 The present study, carried out in collaboration with the Grassy Narrows First Nation community

112 in Northern Ontario, Canada, uses clustering, longitudinal mixed effect models (LMEM) and

113 structural equation models (SEM) to examine the associations between current reported symptoms

114 from GN-CHA survey and retrospective $\mathrm{Hg}$ exposure, using historic biomarker data from a 115 governmental monitoring program.

117 GN-CHA Survey

118 The GN-CHA survey for adults (18 years old and over), initiated in 2015, included 266 questions

119 that covered many aspects of their life and health: demographics, education, generational 120 attendance of residential school, work and income, food consumption, health status, diabetes care, 121 wellness and mental health, injuries, disability, health care access, physical activity, smoking, 122 drinking and drug use, community wellness and traditional culture. Most questions were taken 123 from the First Nation Regional Health Survey 2008/2010 (FNRHS 2008/2010) (27), which

124 provided a basis for comparison with other First Nation communities in Canada. Specific questions

125 were added about fish consumption at different periods of one's life, as well as illnesses and 126 symptoms consistent with $\mathrm{Hg}$ poisoning. The questionnaire was pre-tested with 10 community 127 members in July 2016. A house-to-house survey design was used, with the questionnaire on a web128 based platform.

130 Survey administration was supervised by two field coordinators from Grassy Narrows; nine local 131 interviewers went from house-to-house between December 2016 and March 2017. A total of 213 
132 houses were identified on the reserve; $83.6 \%$ of houses were surveyed. Persons living off-reserve

133 were recruited using convenience sampling. The results of the survey were presented to and

134 discussed with community members during several small group and community meetings. The

135 final report was approved by Chief and Council and a summary was made public on May 24, 2018.

137 A total of 425 adults participated in the survey, of whom 391 (92\%) are Registered Grassy Narrows

138 First Nation members (Band members). At the time of the survey, 303 were living on-reserve and

13988 off-reserve.

141 Biomarkers of mercury exposure

142 At the request of Chief and Council of Grassy Narrows First Nation, the authors obtained from the 143 First Nations and Inuit Health Branch (FNIHB) of the Ministry of Indigenous Services Canada 144 and the Ontario Ministry of Health and Long-term Care, archived Band members' historic 145 biomarker data (hair and/or blood Hg concentrations), gathered between 1970 and 1997 and $\mathrm{Hg}$ 146 umbilical cord Hg data, collected between 1970 and 1992 at the hospital where Grassy Narrows 147 women gave birth.

149 The blood and hair samples were taken as part of a monitoring program of the Medical Research 150 Branch of Health Canada. The objective of the program was to identify persons whose $\mathrm{Hg}$ 151 biomarker concentrations surpassed the guidelines of the time. There was no sampling strategy.

152 The program primarily targeted fishing guides and their families, but anyone could volunteer and 153 provide a sample (4). Some years the sampling period was longer than others and there was no 154 consistency in the month that sampling was carried out. 
156 Samples were analysed for total mercury at Health Canada laboratories $(4,28,29)$. According to

157 Farant et al. 1981 (28), in the initial years, samples were analyzed according to the Magos method 158 (29) and later, a more efficient and less time-consuming method used an improved cold-vapor 159 atomic absorption technique. The two methods were highly correlated for blood $(\mathrm{r}=0.98)$ and hair $160 \quad(\mathrm{r}=0.97)(28)$.

161

162 We assembled a retrospective database using the highest measure of equivalent hair $\mathrm{Hg}$ 163 concentration for each year sampled (6). Since fish consumption varied throughout the year, the

164 corresponding month was also recorded. For the present study, year-based hair Hg measurements $165(\mathrm{n}=1018)$ were available for $208(53.2 \%)$ of the 391 Grassy Narrows Band member participants 166 in the GN-CHA. Of the 211 cord blood samples collected for newborns from Grassy Narrows, 99 167 participated as adults in the GN-CHA, making up 48.5\% of participants born in Kenora between 1681970 and 1992. A total of 242 GN-CHA participants had at least one hair and/or umbilical cord 169 blood Hg measurement.

170

171 Figure 1 shows the breakdown of biomarker sampling among GN-CHA participants. 
176 Direct measurements of hair $\mathrm{Hg}$ over time are presented in Figure 2a. The number of times each

177 person was sampled varied between 1 and $23 ; 75$ persons $(36.1 \%)$ had 5 or more measurements, 178 while $32(15.4 \%)$ had 10 or more.

180 Prenatal Hg exposure

181 Direct measurements $(\mathrm{n}=99)$ of umbilical cord blood were used where available. Estimated Hg 182 values were predicted from linear regression models using the 211 umbilical cord data (Figure 2b) 183 on year of birth for the three periods of $\mathrm{Hg}$ exposure (1970-1976, 1977-1987 and 1988-1992).

184 These estimates were then adjusted on where the person's mother had spent her pregnancy and/or 185 gave birth. For those who were born or whose mother spent her pregnancy in the Wabigoon186 English River region between 1970 and 1992, the mean measured umbilical cord blood $\mathrm{Hg}$ for 187 their year of birth was used. For those born prior to the $\mathrm{Hg}$ discharge in 1962, we attributed $1 \mu \mathrm{g} / \mathrm{L}$ 188 for cord blood $\mathrm{Hg}$, while for those born between 1962 and 1970, mean cord blood $\mathrm{Hg}$ in 1970 was 189 used $(65.7 \mu \mathrm{g} / \mathrm{L})$, and for those born after 1992, mean cord blood Hg from 1992 was applied (4.48 $190 \mu \mathrm{g} / \mathrm{L})$. Finally, for individuals, whose mother spent her pregnancy and delivered elsewhere, cord 191 blood $\mathrm{Hg}$ was set at $1.0 \mu \mathrm{g} / \mathrm{L}$.

192

193 Place Figure 2 here

194

195 Childhood Hg exposure

196 Direct childhood hair Hg measurements were available for 137 GN-CHA participants, for whom 197 we used the mean Hg concentration between 5 and 15 years of age. Figure 3 shows children's 
198 measured hair Hg concentrations for the year in which they were 10 years old, with respect to fish 199 consumption (several times a month vs less). Multiple regression analyses with direct 200 measurements of hair $\mathrm{Hg}$ show significant associations with GN-CHA data on fish consumption 201 at around 10 years of age and residential school attendance (i.e. being outside the community).

203 Place Figure 3 here

204

205 Childhood estimated $\mathrm{Hg}$ was derived from the overall mean hair $\mathrm{Hg}$ in children on the year in 206 which they turned 10 years of age, and then adjusted on reported child fish consumption and having 207 attended a residential school. For participants, who were 10 years old before 1962, hair Hg was set 208 at $0.1 \mu \mathrm{g} / \mathrm{g}$. For those who were 10 years of age between 1962 and 1970, the mean measured hair

$209 \mathrm{Hg}$ in children in 1970 was used. Since there were few data after 1990 and there appears to be a 210 plateau over this last period (Figure 3), we attributed $0.81 \mu \mathrm{g} / \mathrm{g}$ for those who were 10 years of age 211 after 1990. For the 39 participants, who were missing hair $\mathrm{Hg}$ data between 5 and 15 years old and 212 who did not answer the question about childhood fish consumption in the GN-CHA survey, we 213 were unable to estimate childhood Hair Hg exposure.

215 Validity

216 To assess the validity of the estimated measures, we examined the correlations between direct and 217 estimated (indirect) values for both umbilical cord and childhood hair $\mathrm{Hg}$, using non-parametric 218 tests (Spearman). 
221 For the present study, we used the following variables from the GN-CHA: Demographics: age, 222 sex, living on/off reserve, schooling, generational attendance of residential school in the family.

223 Work: currently working (yes/no), currently looking for work (yes/no), reasons for not working

224 (disability or illness/other). Food security: struggle to pay for food once a month or more in the

225 last 6 months. Fish consumption: childhood fish consumption at 10 years of age (5 categories 226 grouped into once a month or less/at least several times a month); walleye consumption over the 227 past year (not at all/a few times/often). Lifestyle: current smoking (yes/no) and current alcohol 228 consumption (heavy drinking (yes/no), defined in the FNRHS 2008/2010 (27) as 5 drinks in one

229 drinking occasion at least once/month in the past 12 months. Health status: obesity (yes/no) was 230 categorized using Body Mass Index $\geq 30 \mathrm{~kg} / \mathrm{m}^{2}$ and at least one reported diagnosed chronic health 231 conditions (yes/no), as listed in the FNRHS 2008/2010 (allergies, arthritis, asthma, cancer, chronic 232 back pain, chronic bronchitis, diabetes, emphysema, heart disease, hepatitis, high blood pressure, 233 liver disease, osteoporosis, rheumatism, stomach or intestinal problems, thyroid problems, and 234 tuberculosis) and at least one diagnosed nervous system disorder (blindness, epilepsy, Bell's palsy, 235 cerebral palsy, muscular dystrophy, Kennedy's disease, Parkinson's diseases, Alzheimer, senile 236 dementia, psychological/nervous disorders, cognitive/mental disorders, Attention deficit 237 hyperactivity orders (ADHD), learning disability).

239 The GN-CHA included 59 self-reported symptoms, rated on a 5-point Likert rating scale ( "Never", 240 "Rarely", "From time to time”, "Very often", “All the time”). Higher scores on the Likert rating 241 scale indicate greater frequency of symptoms. 
244 Self-reported symptoms from the GN-CHA survey $(\mathrm{n}=391)$ were clustered based on their Likert 245 scale, using a simultaneous two-step multivariate segmentation approach (30-32). One is 246 agglomerative and aims at maximising a homogeneity criterion by successively aggregating the 247 variables into clusters using a hierarchical ascendant clustering algorithm. The other is 248 representative and creates a composite variable from a weighted linear combination of symptoms 249 (synthetic variable that can be read as a gradient) for each cluster using a mixed factorial approach 250 (PCAMIX method) (30, 32, 33). For each composite variable (cluster), all participants receive a 251 score based on his/her symptom frequency.

253 A bootstrap approach was used for maximizing the homogeneity criterion within clusters and 254 determining the suitable number of clusters. The desired number of clusters (K) was determined 255 from the analysis of aggregation levels, stability of the partitions via bootstrapped mean-adjusted 256 Rand Index and boxplots. The mean-adjusted Rand index was based on the generation of 60 257 bootstrap samples among all 391 participants. Each cluster was carefully inspected based on its 258 proportion of variation explained (a minimum of 50\% was mandatory) and on degree of 259 "closeness" amongst the symptoms being clustered (a minimum of 0.6 squared correlation of the

260 variable with its composite variable was required). Some symptoms add noise while providing 261 little or no information in identifying the underlying pattern inherent to the cluster (34). Finally, 262 we tested for the "driving" symptoms that best reflect the cluster. We validated the cluster results, 263 using the VARCLUS function of the SAS computer application (JMP Professional 15.0 software). 
265 A confirmatory factor analysis (CFA) was conducted to evaluate the construct validity of symptom

266 clustering using a series of fit parameters (35-39). To achieve this, we used the following: Chi-

267 square divided by the degrees of freedom ( $\chi 2 / \mathrm{df})$, Standardized Root Mean Square Residual

268 (SRMR), Root Mean Square Error of Approximation (RMSEA), Comparative Fit Index (CFI) and

269 Tucker Lewis Index (TLI). Internal consistency (scale reliability) for each cluster was tested using

270 the test of Cronbach alpha $(35,40-42)$. Construct validity for each cluster was also confirmed by

271 the neurologist (T. S. Lena).

272

273 The composite variable serves to validate the clusters based on a factorial approach and provides

274 a measure (gradient). The composite variable, as a measure, is used in the LMEM, but a latent

275 variable, which bonds the symptoms in the cluster into a construct is used in the SEM.

277 Longitudinal mixed effects models

278 LMEMs were performed using direct measurements of longitudinal hair $\mathrm{Hg}$ with respect to the 279 composite variable for each cluster. We chose mixed effect modeling (MEM) as it is robust to 280 missing data and irregularly spaced sampling; it also handles both time-invariant and time-varying 281 covariates (43). MEM enables multilevel modeling and partitioning of the covariance structure 282 (random effects). We tested the following fixed and/or random effects for covariates (age category, 283 sex, year of sampling, socioeconomical status, lifestyle and medical history, age at sampling and 284 sampling season). The covariates were kept in the MEM if they showed a p-value $<=0.10$ or if 285 they substantively altered the cluster ( $\geq 20 \%$ change). The normality of residuals was tested using 
286 a q-q plot. The most appropriate model was selected using the Akaike Information Criterion (AIC),

287 the Baysian Information Criteria (BIC) and the likelihood ratio (LR) test at $\mathrm{p}<=0.05$.

288

289 For the longitudinal approach, LMEM requires repeated measures. Because of the absence of a 290 biomarker sampling strategy, over half (56\%) of the 208 persons with hair $\mathrm{Hg}$ measurements had

2913 repeated measurements or less. Despite the flexibility of MEM with missing data, we preferred 292 not to impute Hg levels for people whose diet and environmental context varied over time, 293 particularly when living off-reserve. For the LMEM, we only included participants with at least 294 hair Hg measurements (17 men and 15 women; total of 447 hair $\mathrm{Hg}$ measurements, covering a 295 period from 10 to 23 years (median 21 years).

297 To ensure that there were sufficient observations for the analyses, we estimated the minimal 298 required sample size, based on formulas from Hedeker and co-authors (44) and direct calculations 299 using the G*power software (45-47). Since one centimeter of a hair sample represents an 300 accumulation of $\mathrm{Hg}$ during approximately one month (48), we used a low correlation of repeated 301 measures between yearly-based samples (rho 0.1 and 0.2 ). Because the effect size was unknown, 3020.25 was chosen. Power analyses were set at $80 \%$, with a two-tailed $5 \%$ hypothesis test, and 10 303 time points; the minimal number of participants required was between 29 and 33.

\section{Structural equation models}

306 SEM is a comprehensive methodology for representing, estimating, and simultaneously testing a 307 network of complex relationships. This multivariate technique can incorporate observed 308 (measured) and unobserved variables (latent), while traditional techniques only allows for 
measured variables. The latent variable is an unobservable multidimensional construct that cannot

310 be directly measured $(49,50)$.

312 In the SEM for the symptom clusters, we use the latent variable rather than the composite variable

313 because it better reflects the structural concept of co-occurring symptoms. A latent variable is

314 likewise used for $\mathrm{Hg}$ exposure at different times (prenatal, childhood and having had $\geq 5 \mu \mathrm{g} / \mathrm{m} \mathrm{hair}$

$315 \mathrm{Hg}$ at least once over the monitoring period).

317 SEM allows for data from multiple exposures and multiple outcomes to be considered 318 simultaneously (51). It is based on an interrelated system of linear regression equations that extend 319 the possibility of relations between observed and latent variables, as well as direct and indirect 320 (mediation) relations and allows for flexibility in modeling covariance structures $(19,39,52,53)$.

321 Finally, SEM provides path diagrams that are useful to understand and interpret the contribution 322 of the various variables. The standardized factor loadings allow for pathway comparison.

324 For the SEMs, we tested the associations between each cluster and $\mathrm{Hg}$ exposure, represented either 325 by a latent variable (Latent $\mathrm{Hg}$ ) or by separate prenatal, childhood and having had $5 \mu \mathrm{g} / \mathrm{g}$ hair $\mathrm{Hg}$ 326 at least once in their lifetime (Hair $\mathrm{Hg} \geq 5 \mu \mathrm{g} / \mathrm{g}$ ) in the same model. Covariates (age category, sex, 327 year of sampling, residence, socioeconomic status, lifestyle, obesity and medical history) were 328 kept in the model at a p-value $<=0.10$ or if they substantively altered the model ( $\geq 20 \%$ change).

330 For each cluster, we verified possible mediation between covariates and $\mathrm{Hg}$ exposure (individual 331 variables or Latent $\mathrm{Hg}$ ) and the dependent latent cluster symptoms variable. Given the expected 
332 association of prenatal $\mathrm{Hg}$ exposure with childhood $\mathrm{Hg}$ exposure in the context of a high fish-

333 consuming population, we tested whether childhood $\mathrm{Hg}$ exposure mediated the relation between

334 prenatal $\mathrm{Hg}$ exposure and the dependent latent cluster symptoms variable. Mediation through hair

$335 \mathrm{Hg} \geq 5 \mu \mathrm{g} / \mathrm{g}$ was also tested. Finally, we tested whether sex modified the relation between past $\mathrm{Hg}$

336 exposures, covariates, and the latent cluster symptoms variable (moderation). Moderated

337 mediation was also tested in SEM with age and sex variables.

339 Variables with a skewed distribution were log (base 10) transformed. Because latent variables, $\mathrm{Hg}$ 340 exposures and covariates, are all on different scales, we used standardized path coefficients to test

341 the magnitude of relations. Standardized coefficients indicate the expected amount of change in

342 standard deviation (SD) in the dependent latent symptoms cluster for an increase of one SD in the

343 predictor, while other predictors (covariates) are kept constant. The adequacy of model fit to the

344 data was determined using multiple tests, $\chi 2 / \mathrm{df}$, CFI, TLI, RMSEA, SRMR and Akaike's

345 Information Criterion (AIC) and Schwarz's Bayesian information criterion (BIC) (35-39).

346 Diagonally weighted least squares (DWLS) adjustments in SEM were used to take into account

347 the ordinal nature of symptom frequency outcomes. To improve the reliability of the latent

348 construct's scale or the models, we examined residual variances between indicators. Modification

349 indices (MI) were used to assess the addition or deletion of variables and/or associations to

350 improve the goodness of fit of the SEM. The sequence of initial fit, modification (MI) and refitting

351 were repeated until the best fit SEM was attained.

352

353 To ensure that the database of 242 participants was sufficient to run SEM, two types of power 354 analyses were performed: i) to detect model misspecification and ii) to detect target effect 
355 (influence of $\mathrm{Hg}$ exposure on the symptom cluster) (54). A-priori, post-hoc, and compromise 356 power-analyses were run simultaneously to detect model misspecification based on Chi-square

357 likelihood-ratio and RMSEA tests of close and not-close fit, (55-58). The power for detecting 358 specific target effect was determined with simulated data in SEM (54).

360 For the SEM, validated prenatal and childhood Hg exposure estimates, described above, were used 361 when there was no measurement, while for GN-CHA variables, missing data were handled and 362 imputed using Multivariate Imputation by Chained Equations (MICE).

364 To support the SEM, we ran a series of Directed Acyclic Graphs (DAG) for sensitivity analyses.

365 DAG is a visual representation of causal assumptions that makes underlying relations explicit. It 366 is used to detect overt bias, notably through backdoor paths that identify the presence of 367 confounding $(59,60)$. Modifications to DAG-implied adjustment sets include conditioning 368 confounding and variables with ambiguous causing roles $(61,62)$.

370 Threshold of statistical significance in all analyses was set at $\mathrm{p} \leq 0.05$.

372 Database management and descriptive statistical analyses were performed using JMP Professional 37315.0 (Statistical Analysis Hardware (SAS Institute). LMEM were conducted with Stata 16 374 software (StataCorp. 2019. Stata Statistical Software: Release 16.0. College Station, TX: Stata 375 Corporation). All other analyses were computed using the R statistical software version 3.6.1. (R 376 Core Team, 2016). We used the R package ClustOfVar (31) for clustering analyses and the MICE 377 (Multiple Imputation by Chained Equations) package for multiple imputation of missing data in 
378 CFA and SEM. PairedData and dplyr packages were used for paired-t tests. CFA and SEM models

379 were computed with the R package Lavaan (39). The dagitty and ggdag R packages were used for

380 analysing SEM and DAG. A-priori, post-hoc, and compromise power-analyses were computed

381 using the semPower package. To assess power for detecting a target effect in SEM we used an

382 online tool: yilinandrewang.shinyapps.io/pwrSEM/ (63).

\section{Results}

387 Relevant characteristics of the 391 adults who participated in the GN-CHA study and whose data 388 was used for symptom clustering, are presented by age category in Tables 1 and 2 . In this 389 community, age also reflects changes in Hg exposure over time. Almost half of the participants 390 are between 30 and 49 years of age, with no difference in age distribution between women and 391 men. There are important age differences in schooling. Proportionally fewer older persons had 392 attended high school, however, over half of those 30 years and older had furthered their education 393 through post-secondary training programs (data not shown). In Canada, First Nation children were 394 placed, often forcibly, in residential schools, with harmful effects on themselves and their families 395 (64, 65). In the present study, no one born after 1978 had attended residential school; for those 396 born prior to this date, 58 persons $(50.0 \%)$ had been in a residential school, while for their mothers 397 and/or fathers, it was $95.4 \%$. At the time of the survey, $51.1 \%$ of women and $43.1 \%$ of men are 398 working, excluding persons studying, retired or at home with children $(\mathrm{n}=32)$. Among participants 399 who report not working, $78 \%$ of those between 18 and 49 years of age are looking for work, while 
31 persons $(68.9 \%)$ of those over 30 years of age, who are not looking for work, report that it is

401 due to illness or disability.

402

403 There is no age difference for difficulty paying for food, which is reported by almost $25 \%$ of 404 participants. The prevalence of current smokers and heavy drinkers significantly decreases with 405 age. Obesity is most prevalent among those 30-49 years old, of whom two-thirds are women. Sixty 406 percent of participants report that a health professional had told them that they have at least one 407 chronic health condition; the prevalence increases significantly with age.

408

409 Table 1. The relative frequency of the characteristics of the population within each age category.

\begin{tabular}{|c|c|c|c|c|c|c|}
\hline & $\mathrm{N}^{\mathrm{a}}$ & $\begin{array}{c}18-29 y \\
n \\
(\%)\end{array}$ & $\begin{array}{c}30-49 \mathrm{y} \\
\mathrm{n} \\
(\%)\end{array}$ & $\begin{array}{c}50+y \\
n \\
(\%)\end{array}$ & $\begin{array}{c}\text { Total } \\
\mathrm{n} \\
(\%)\end{array}$ & $\begin{array}{c}\text { Chi-square } \\
\text { (LR) } \\
\text { p-value }\end{array}$ \\
\hline $\begin{array}{l}\text { Sex } \\
\text { Women } \\
\text { Men }\end{array}$ & 391 & $\begin{array}{c}66 \\
(53.3 \%) \\
58 \\
(46.7 \%)\end{array}$ & $\begin{array}{c}97 \\
(51.6 \%) \\
72 \\
(48.4 \%)\end{array}$ & $\begin{array}{c}48 \\
(60.8 \%) \\
31 \\
(39.2 \%)\end{array}$ & $\begin{array}{c}211 \\
(54 \%) \\
180 \\
(46 \%)\end{array}$ & $\begin{array}{l}1.94 \\
0.380\end{array}$ \\
\hline Living on reserve & 390 & $\begin{array}{c}95 \\
(76.6 \%)\end{array}$ & $\begin{array}{c}144 \\
(77.0 \%)\end{array}$ & $\begin{array}{c}62 \\
(78.5 \%)\end{array}$ & $\begin{array}{c}301 \\
(77.2 \%)\end{array}$ & $\begin{array}{c}0.10 \\
0.949\end{array}$ \\
\hline $\begin{array}{l}\text { Schooling } \\
\text { Attended school }\end{array}$ & 382 & 122 & 180 & 75 & $37^{\prime}$ & 4.13 \\
\hline & & $(100 \%)$ & $(98.4 \%)$ & $(97.4 \%)$ & $(98.7 \%)$ & 0.257 \\
\hline Attended high school & 366 & $\begin{array}{c}115 \\
(98.3 \%)\end{array}$ & $\begin{array}{c}166 \\
(94.9 \%)\end{array}$ & $\begin{array}{c}48 \\
(64.9 \%)\end{array}$ & $\begin{array}{c}329 \\
(89.9 \%)\end{array}$ & $\begin{aligned} & 52.6 \\
< & 0.0001\end{aligned}$ \\
\hline Other education & 386 & $\begin{array}{c}33 \\
(27.1 \%)\end{array}$ & $\begin{array}{c}108 \\
(58.4 \%)\end{array}$ & $\begin{array}{c}43 \\
(54.4 \%)\end{array}$ & $\begin{array}{c}184 \\
(47.7 \%)\end{array}$ & $\begin{array}{c}31.69 \\
<0.0001 \\
\end{array}$ \\
\hline Residential school & & & & & & \\
\hline Attended residential school & 376 & 0 & $\begin{array}{c}6 \\
(3.4 \%)\end{array}$ & $\begin{array}{c}52 \\
(66.7 \%)\end{array}$ & $\begin{array}{c}58 \\
(15.4 \%)\end{array}$ & $\begin{array}{c}171 \\
<0.0001\end{array}$ \\
\hline Parents in residential school & 326 & $\begin{array}{c}36 \\
(40.5 \%)\end{array}$ & $\begin{array}{c}148 \\
(89.7 \%)\end{array}$ & $\begin{array}{c}68 \\
(94.4 \%)\end{array}$ & $\begin{array}{c}252 \\
(77.3 \%)\end{array}$ & $\begin{array}{c}89 \\
<0.0001\end{array}$ \\
\hline $\begin{array}{l}\text { Work activities } \\
\quad \text { Currently working }\end{array}$ & 349 & $\begin{array}{c}39 \\
(37.5 \%)\end{array}$ & $\begin{array}{c}94 \\
(52.2 \%)\end{array}$ & $\begin{array}{c}32 \\
(48.5 \%)\end{array}$ & $\begin{array}{c}165 \\
(49.2 \%)\end{array}$ & $\begin{array}{c}5.90 \\
0.052\end{array}$ \\
\hline Currently looking for work ${ }^{\mathrm{c}}$ & 165 & $\begin{array}{c}45 \\
(81.8 \%)\end{array}$ & $\begin{array}{c}58 \\
(75.3 \%)\end{array}$ & $\begin{array}{c}7 \\
(21.2 \%)\end{array}$ & $\begin{array}{c}110 \\
(66.7 \%)\end{array}$ & $\begin{array}{c}38.2 \\
<0.0001\end{array}$ \\
\hline $\begin{array}{l}\text { Struggle to pay for food } \\
\text { monthly or more in the last year }\end{array}$ & 332 & $\begin{array}{c}28 \\
(26.9 \%)\end{array}$ & $\begin{array}{c}38 \\
(24.2 \%)\end{array}$ & $\begin{array}{c}17 \\
(23.9 \%)\end{array}$ & $\begin{array}{c}83 \\
(25.0 \%)\end{array}$ & $\begin{array}{c}3.65 \\
0.392\end{array}$ \\
\hline Current smoker & 376 & $\begin{array}{c}54 \\
(46.2 \%)\end{array}$ & $\begin{array}{c}90 \\
(49.7 \%)\end{array}$ & $\begin{array}{c}24 \\
(30.8 \%)\end{array}$ & $\begin{array}{c}168 \\
(44.7 \%)\end{array}$ & $\begin{array}{c}0.28 \\
0.016\end{array}$ \\
\hline
\end{tabular}




\begin{tabular}{l|c|c|c|c|c|c} 
Heavy drinker & 360 & $\begin{array}{c}79 \\
(71.2 \%)\end{array}$ & $\begin{array}{c}100 \\
(56.8 \%)\end{array}$ & $\begin{array}{c}20 \\
(27.4 \%)\end{array}$ & $\begin{array}{c}199 \\
(55.3 \%)\end{array}$ & $\begin{array}{c}35.3 \\
\end{array}$ \\
\hline Obese & 375 & 47 & 93 & 36 & 176 & 4.0001 \\
& & $(39.8 \%)$ & $(51.7 \%)$ & $(46.8 \%)$ & $(46.9 \%)$ & 0.133 \\
\hline $\begin{array}{l}\text { At least one diagnosed chronic } \\
\text { health condition }\end{array}$ & 385 & 46 & 117 & 67 & 230 & 46.6 \\
\hline $\begin{array}{l}\text { At least one diagnosed nervous } \\
\text { system disorder }\end{array}$ & 381 & $(38.3 \%)$ & $(62.9 \%)$ & $(84.8 \%)$ & $(59.7 \%)$ & $<0.0001$ \\
\hline
\end{tabular}

$411 \quad{ }^{a}$ Number (N) of valid responses (does not include don’t know or don't remember and refused).

412 bLikelihood Ratio Chi-square compares the relative frequency between age categories.

$413{ }^{\mathrm{c}}$ Excludes students, stay at home parents and retirees.

415 There are no differences between men and women for age distribution, schooling, having attended 416 or having parents who attended residential school, difficulty paying for food, and current smoking.

417 Proportionally more men report heavy drinking compared to women (62.7\% vs 48.7\%; Chi-square

418 LR 7.17; $\mathrm{p}=0.007)$, while women have a significantly higher prevalence of obesity $(54.0 \%$ vs

$41938.9 \%$; Chi-square LR: 14.01, $\mathrm{p}=0.003$ ) and at least one chronic health condition diagnosed by a 420 health professional (68.5\% vs 49.7\%; Chi-square LR: $14.01, \mathrm{p}=0.0001)$.

422 In this community, fish, especially walleye, is the source of $\mathrm{Hg}$ exposure $(4,5)$. Table 2 contains 423 the responses to the GN-CHA questions on past and current fish consumption frequency. In 424 response to the question about fish consumption at around 10 years old, 46 persons (12.1\%) 425 respond that they do not remember. Among the others, over half of those 50 years and older (born 426 before 1968) report that, as a child, they ate fish daily. Childhood fish consumption frequency 427 significantly decreased over time. Fish consumption questions were species specific. Walleye is 428 still the fish the most consumed; 30.6\% of GN-CHA participants report eating walleye often 429 compared to $4.7 \%$ for whitefish and 3.2\% for northern pike. No differences are observed between 
430 women and men for the frequency of childhood or current fish consumption.

432 Table 2. The relative frequency of fish consumption by age category

\begin{tabular}{|c|c|c|c|c|c|c|}
\hline & $\mathrm{N}$ & $\begin{array}{c}18-29 y \\
\mathrm{n} \\
(\%)\end{array}$ & $\begin{array}{c}30-49 \mathrm{y} \\
\mathrm{n} \\
(\%)\end{array}$ & $\begin{array}{c}50+y \\
n \\
(\%)\end{array}$ & $\begin{array}{c}\text { Total } \\
\mathrm{n} \\
(\%)\end{array}$ & $\begin{array}{c}\text { Chi-square } \\
\text { (LR) } \\
\text { p-value }\end{array}$ \\
\hline Fish consumption at $10 \mathrm{y}$ of age & 333 & & & & & \\
\hline None & & $\begin{array}{c}9 \\
(9.4 \%)\end{array}$ & $\begin{array}{c}10 \\
(6.1 \%)\end{array}$ & $\begin{array}{c}4 \\
(5.5 \%)\end{array}$ & $\begin{array}{c}23 \\
(6.9 \%)\end{array}$ & $\begin{array}{c}101 \\
<0.0001\end{array}$ \\
\hline Hardly ever/occasionally & & $\begin{array}{c}32 \\
(33.3 \%)\end{array}$ & $\begin{array}{c}26 \\
(15.9 \%)\end{array}$ & $\begin{array}{c}3 \\
(4.1 \%)\end{array}$ & $\begin{array}{c}61 \\
(18.3 \%)\end{array}$ & \\
\hline Once a month & & $\begin{array}{c}24 \\
(25.0 \%)\end{array}$ & $\begin{array}{c}38 \\
(23.2 \%)\end{array}$ & $\begin{array}{c}2 \\
(2.7 \%)\end{array}$ & $\begin{array}{c}64 \\
(19.2 \%)\end{array}$ & \\
\hline Several times a month & & $\begin{array}{c}28 \\
(29.2 \%)\end{array}$ & $\begin{array}{c}96 \\
(42.1 \%)\end{array}$ & $\begin{array}{c}24 \\
(32.9 \%)\end{array}$ & $\begin{array}{c}121 \\
(36.4 \%)\end{array}$ & \\
\hline Every day & & $\begin{array}{c}3 \\
(3.1 \%)\end{array}$ & $\begin{array}{c}21 \\
(12.8 \%)\end{array}$ & $\begin{array}{c}40 \\
(54.8 \%)\end{array}$ & $\begin{array}{c}64 \\
(19.2 \%)\end{array}$ & \\
\hline Walleye consumption over past year & 382 & & & & & \\
\hline Not at all & & $\begin{array}{c}23 \\
(19.5 \%)\end{array}$ & $\begin{array}{c}29 \\
(15.7 \%)\end{array}$ & $\begin{array}{c}9 \\
(11.4 \%)\end{array}$ & $\begin{array}{c}61 \\
(16.0 \%)\end{array}$ & $\begin{array}{c}3.44 \\
0.486\end{array}$ \\
\hline A few times & & $\begin{array}{c}60 \\
(50.9 \%)\end{array}$ & $\begin{array}{c}96 \\
(51.9 \%)\end{array}$ & $\begin{array}{c}48 \\
(60.8 \%)\end{array}$ & $\begin{array}{c}204 \\
(53.4 \%)\end{array}$ & \\
\hline Often & & $\begin{array}{c}35 \\
(29.7 \%)\end{array}$ & $\begin{array}{c}60 \\
(32.4 \%)\end{array}$ & $\begin{array}{c}22 \\
(27.9 \%)\end{array}$ & $\begin{array}{c}117 \\
(30.6 \%)\end{array}$ & \\
\hline
\end{tabular}

434 Likelihood Ratio Chi-square compares the relative frequency between age categories

436 Biomarkers of $\mathrm{Hg}$ exposure decrease over the time period (Figure 2a, 2b, 3, and Table 3), 437 paralleling the decrease in fish consumption. There is a positive association between childhood 438 fish consumption and measured Hair Hg, adjusted for sex and year of sampling (MEM: Wald Chi439 square $=96.85 ; \mathrm{p}=0.003$ ). Paired t-tests, comparing mean hair $\mathrm{Hg}$ at 10 years of age, for each 440 year, between those who report eating fish during childhood at least several times a month and 441 those who report eating less, support the MEM result (Wilcoxon Signed-Rank prob $>|S|$, S: 37.5; $p$ $442=0.02)$. 
Table 3. Measured mercury concentrations by age category

\begin{tabular}{|c|c|c|c|c|c|c|}
\hline & $\bar{N}$ & $\begin{array}{c}18-29 \text { y } \\
\text { Median } \\
\text { (min-max) }\end{array}$ & $\begin{array}{c}30-49 \text { y } \\
\text { Median } \\
\text { (min-max) }\end{array}$ & $\begin{array}{c}50^{+} \mathrm{y} \\
\text { Median } \\
\text { (min-max) }\end{array}$ & $\begin{array}{c}\text { Total } \\
\text { Median } \\
\text { (min-max) }\end{array}$ & $\begin{array}{c}\text { Wilcoxon } \\
\text { test } \\
\text { p-value }\end{array}$ \\
\hline $\begin{array}{l}\text { Umbilical cord } \\
(\mathrm{ppb})\end{array}$ & 99 & $\begin{array}{c}3.5 \\
(1.5-10)\end{array}$ & $\begin{array}{c}5.6 \\
(1-78.5)\end{array}$ & & $\begin{array}{c}5 \\
(1-78.5)\end{array}$ & 0.023 \\
\hline $\begin{array}{l}\text { Childhood Hair Hg } \\
(\mu \mathrm{g} / \mathrm{g})\end{array}$ & 137 & $\begin{array}{c}0.9 \\
(0.5-2)\end{array}$ & $\begin{array}{c}0.7 \\
(0.2-16)\end{array}$ & $\begin{array}{c}2.9 \\
(0.6-15)\end{array}$ & $\begin{array}{c}1.1 \\
(0.2-16)\end{array}$ & $<0.0001$ \\
\hline $\begin{array}{l}\text { Hair } \geq \operatorname{Hg} 5 \mu \mathrm{g} / \mathrm{g} \\
\text { at least once }\end{array}$ & 208 & 0 & $\begin{array}{c}27 \\
(22.9 \%)\end{array}$ & $\begin{array}{c}49 \\
(74.2 \%)\end{array}$ & $\begin{array}{c}76 \\
(36.6 \%)\end{array}$ & $<0.0001$ \\
\hline
\end{tabular}

447 Figure 4 presents the aggregation levels and construct stability of the clusters. Aggregation 448 distances support a cutting threshold between 5 and 8 clusters (Figure 4a), while the bootstrapped 449 mean-adjusted $\mathrm{R}$ and criterion suggest 6, 7, 11, or 12 (Figure 4b). The boxplots (Figure 4c) show 450 that the highest stability of the partition solution varies between $\mathrm{K} 5$ and $\mathrm{K}$, with $\mathrm{K} 7$ showing a 451 slightly higher median value, but a lower dispersion around the mean. After verification of all of 452 the above criteria, we kept a total of six clusters. Goodness of fit for CFA was acceptable for the 453 six clusters $(\mathrm{CFI}=0.85, \mathrm{TLI}=0.84, \mathrm{RMSEA}=0.08, \mathrm{SRMR}=0.05)$; with a narrow $90 \% \mathrm{CI}$, 454 representing a high degree of precision. The Cronbach alpha $(>0.8)$ for each cluster confirmed 455 internal consistency (Table 4).

457 Place Figure 4 here

459 The six clusters include a total of 37 symptoms. Table 4 presents the list of symptoms retained in 460 each cluster with its correlation. Cluster 1 (Extrapyramidal impairment), which aggregates the 461 highest number of symptoms $(n=9)$, includes tremors, balance impairment, functional limb 
462 weakness and pain in arms and legs, reflecting an extension of extrapyramidal neurological

463 symptoms. Cluster 2 (Sensory impairment) groups peripheral neuropathic deficits, notably upper

464 and lower limb sensory impairments including numbness, dullness and tingling. Cluster 3 (Cranial

465 nerve disturbances) includes anosmia, ageusia, dysphagia and tingling around the mouth. Cluster 4

466 (Gross motor impairment) aggregates symptoms that affect carrying, lifting and walking. Cluster 5

467 (Neuro-cognitive deficits) groups cognitive dysfunction associated with memory loss, hearing 468 impairment and speech disorders. Finally, Cluster 6 (Affect/Mood disorders) includes anxiety, 469 irritability, depression and sleeping issues. For each cluster, there is no particular driving symptom.

470 Most symptoms are highly related to their own cluster (Table 4).

472 Place Table 4 (large table)

474 For the large majority of symptoms, no significant difference is observed in the proportion of men 475 and women who report its frequency as very often/ all the time (Table 4). Symptom frequency 476 increases significantly with age (data not shown), with the exception of difficulty pronouncing 477 words, forgetting to do things, doing nothing, irritability, anxiety, difficulty falling asleep, waking 478 up at night, depressed, tiredness and difficulty concentrating (Fisher's Exact Test; all $\mathrm{p} \geq 0.08$ ).

480 Table 5 presents the descriptive characteristics of the composite variable for each cluster for 481 women and men. A higher score in the composite variable reflects a higher frequency of coexisting 482 symptoms. Scores are significantly higher in women than in men, with the exception of Neuro483 cognitive deficits. Scores increase significantly with age (Rho: $0.138-0.409 ; p<0.01$ ), with the 484 exception of Affect/Mood disorders (Rho: 0.108; $\mathrm{p}=0.095$ ). 
Table 5. Descriptive characteristics of the composite variable in each cluster

\begin{tabular}{|c|c|c|c|c|}
\hline \multirow[t]{2}{*}{ Clusters } & \multicolumn{3}{|c|}{$\begin{array}{c}\text { Component Score } \\
\text { Mean, Median (min-max) }\end{array}$} & \multirow[t]{2}{*}{$\begin{array}{l}\text { Wilcoxon } \\
\text { p-value }\end{array}$} \\
\hline & All & Women & Men & \\
\hline Cluster 1 (Extrapyramidal impairment) & $\begin{array}{l}2.7,2.2 \\
(0-11.2)\end{array}$ & $\begin{array}{l}3.0,2.6 \\
(0-1.2)\end{array}$ & $\begin{array}{l}2.3,1.7 \\
(0-9.1)\end{array}$ & 0.002 \\
\hline Cluster 2 (Sensory impairment) & $\begin{array}{l}2.6,2.4 \\
(0-8.3)\end{array}$ & $\begin{array}{l}2.8,2.8 \\
(0-8.3)\end{array}$ & $\begin{array}{l}2.3,2.1 \\
(0-8.3)\end{array}$ & 0.012 \\
\hline Cluster 3 (Cranial nerve disturbances) & $\begin{array}{c}1.4,0.9 \\
(0-7.9)\end{array}$ & $\begin{array}{l}1.6,1.0 \\
(0-7.9)\end{array}$ & $\begin{array}{c}1.1,0.4 \\
(0-6.9)\end{array}$ & 0.017 \\
\hline Cluster 4 (Gross motor impairment) & $\begin{array}{l}1.4,0.7 \\
(0-6.6)\end{array}$ & $\begin{array}{l}1.8,1.1 \\
(0-6.6)\end{array}$ & $\begin{array}{l}1.0,0.3 \\
(0-6.2)\end{array}$ & 0.000 \\
\hline Cluster 5 (Neuro-cognitive deficits) & $\begin{array}{l}2.3,2.1 \\
(0-8.0)\end{array}$ & $\begin{array}{l}2.4,2.3 \\
(0-8.0)\end{array}$ & $\begin{array}{l}2.1,2.0 \\
(0-7.2)\end{array}$ & 0.199 \\
\hline Cluster 6 (Affect/Mood disorders) & $\begin{array}{l}4.3,4.3 \\
(0-10.4)\end{array}$ & $\begin{array}{l}4.7,4.9 \\
(0-10.4)\end{array}$ & $\begin{array}{l}3.8,4.0 \\
(0-10.1)\end{array}$ & 0.000 \\
\hline
\end{tabular}

489 Table 6 presents the results of the longitudinal MEMs, which include the 32 participants with at

490 least 10 direct hair $\mathrm{Hg}$ measurements. The associations between longitudinal hair $\mathrm{Hg}$ and the 491 median of the composite variable for each cluster are shown; age, sex and year of sampling are 492 included as fixed factors, and age at time of sampling as random factor. In these analyses, 5 of the 4936 clusters are significantly associated $(\mathrm{p} \leq 0.05)$ or show a tendency $(<0.10)$ with longitudinal hair $494 \mathrm{Hg}$. No association is observed between longitudinal hair Hg and Affect/Mood disorders. variable) from 1970 to 1997 for persons whose composite symptom cluster variable scores are above the median compared to those below above the median. 


\begin{tabular}{|c|c|c|c|}
\hline Composite symptom cluster variable $^{\mathrm{a}, \mathrm{b}}$ & $\begin{array}{c}\text { Hair Hg } \\
\text { Estimate }^{\mathrm{c}}\end{array}$ & $\begin{array}{l}\text { \% Confidence } \\
\text { Interval }\end{array}$ & $\begin{array}{c}\mathrm{p}- \\
\text { value }\end{array}$ \\
\hline Cluster1 (Extrapyramidal impairment) & 1.76 & $0.0-3.6$ & 0.061 \\
\hline Cluster2 (Sensory impairment) & 1.57 & $-2.7-3.4$ & 0.096 \\
\hline Cluster3 (Cranial nerve disturbances) & 2.60 & $1.0-4.2$ & 0.001 \\
\hline Cluster4 (Gross motor impairment) & 2.70 & $0.4-5.1$ & 0.023 \\
\hline Cluster5 (Neuro-cognitive deficits) & 2.41 & $0.6-4.2$ & 0.009 \\
\hline Cluster6 (Affect/Mood disorders) & -0.33 & $-0.3-1.0$ & 0.758 \\
\hline
\end{tabular}

$501{ }^{a}$ Only participants with 10 measurements and more of hair $\mathrm{Hg}$ are included in the analyses (32 persons; $447 \mathrm{Hair} \mathrm{Hg}$ 502 measurements).

$503{ }^{\mathrm{b}}$ Significant covariates include age, sex, year of sampling (random effect: age of sampling nested in year of 504 sampling).

$505{ }^{\mathrm{c}} \mathrm{Hair} \mathrm{Hg}$ estimates represent the increase in Hair $\mathrm{Hg}$ for each unit of the cluster score over the sampling period.

507 The 242 GN-CHA participants selected for the SEMs present similar characteristics to the 391 508 participants presented in Tables 1 and 2, although they are slightly older (median: 39 years old; $50925^{\text {th }}-75^{\text {th }}$ percentile: $\left.32-50\right)$, with proportionally fewer persons in the $18-29$ category $(11.5 \%$ vs $51028.8 \%$ ). In these analyses, both measured and estimated $\mathrm{Hg}$ values are used. Validation of 511 estimated $\mathrm{Hg}$ values show significant associations with direct measurements for both prenatal and 512 childhood $\mathrm{Hg}$ exposure $(\mathrm{n}=99 ; \mathrm{Rho}=0.22 ; \mathrm{p}=0.023$ and $\mathrm{n}=137$; Rho $=0.73 ; \mathrm{p}<0.0001$, 513 respectively). Most participants $(n=197(81.4 \%))$ were born after 1962 (when exposure began) 
514 and had both pre- and post-natal exposures. Only 8 of the 242 participants (3.3\%) were over 15

515 years of age in 1962.

516

517 For each symptom cluster, SEMs were performed (i) with latent $\mathrm{Hg}$ and (ii) with prenatal, 518 childhood and hair $\mathrm{Hg} \geq 5 \mu \mathrm{g} / \mathrm{g}$ separately. Path diagrams, showing the configuration of the

519 different pathways and the one-to-one relation between variables, are illustrated in Figures 5 and 5206 and in Supplementary Figures 1-10 in Additional File 1. SEM standardized path coefficients, 521 representing the total quantified contribution of significant direct and indirect associations, are 522 presented in Figures 7 and 8.

524 Place Figures 5 and 6 here

526 Place Figures 7 and 8 here

528 For all latent $\mathrm{Hg}$-based SEMs, childhood $\mathrm{Hg}$ exposure and hair $\mathrm{Hg} \geq 5 \mu \mathrm{g} / \mathrm{g}$ are the main drivers 529 in the construct of latent $\mathrm{Hg}$ (Figures 5 and 7). Latent $\mathrm{Hg}$ shows a direct contribution on most 530 symptom clusters, but not Neuro-cognitive deficits and Gross motor impairment. For all clusters, 531 there is also an indirect pathway for Latent $\mathrm{Hg}$, mediated through having at least one diagnosed 532 nervous system disorder.

534 In every SEM with separate $\mathrm{Hg}$ exposure variables for prenatal, childhood and hair $\mathrm{Hg} \geq 5 \mu \mathrm{g} / \mathrm{g}$, 535 there is a significant relation between prenatal and childhood exposure (Figures 6 and 8 and 536 Supplementary Figures 6-10, Additional File 1). For Extrapyramidal Impairment (Figure 6) and 
537 for Cranial Nerve Disturbances (Supplementary Figure 7, Additional File 1), standardized path 538 coefficients show that the contribution of prenatal exposure to the cluster is mediated by childhood 539 exposure.

541 For Sensory Impairment (Supplementary Figure 6, Additional File 1), Gross Motor Impairment 542 (Supplementary Figure 8) and Neuro-cognitive Deficits (Supplementary Figure 9, Additional File

543 1) there is a chain of mediation from prenatal exposure to childhood exposure and from childhood

544 to being diagnosed with at least one nervous disorder. When the same chain of mediation is 545 modelled for Extrapyramidal and for Cranial Nerve Disturbances, the models' fit parameters are 546 weaker. In these cases, the direct association of childhood $\mathrm{Hg}$ with the symptom cluster is higher 547 than its indirect association through diagnosed nervous disorder.

549 Prenatal $\mathrm{Hg}$ exposure is directly associated with the cluster of Affect/Mood disorders 550 (Supplementary Figure 10, Additional File 1). Having had $\mathrm{Hg} \geq 5 \mu \mathrm{g} / \mathrm{g}$ directly influences 551 Extrapyramidal Impairment and Sensory Impairment (Figure 6 and Supplementary Figure 6, 552 respectively).

554 Analyses of separate SEM for each type of $\mathrm{Hg}$ exposure show direct and significant relationships 555 for prenatal $\mathrm{Hg}$ exposure with Extrapyramidal impairment, Cranial nerve disturbances and 556 Affect/Mood disorders (data not shown). Childhood Hg exposure shows significant associations 557 for Extrapyramidal impairment, Cranial nerve disturbances and Neuro-cognitive deficits. Having $558 \mathrm{had} \geq 5 \mu \mathrm{g} / \mathrm{g}$ hair $\mathrm{Hg}$ at least once shows significant associations for Extrapyramidal and Sensory 559 Impairment and a tendency for Cranial nerve disturbances (data not shown). 
561 The best fit models are those that include childhood exposure as mediator for prenatal exposure.

562 Childhood is not a confounding variable in the relation between prenatal exposure, diagnosed

563 nervous system disorder or any symptom cluster. Moreover, there is no moderated mediation with

564 age category or $\mathrm{Hg}$ exposure in the SEM.

566 Although of different magnitudes, age category, sex and obesity, at least one diagnosed chronic

567 health condition and at least one diagnosed nervous system disorder, directly and/or indirectly 568 influence symptom frequency in all SEMs. Positive associations are observed with age category

569 with respect to diagnosed nervous system and health conditions, with the exception of Affect $/ \mathrm{mood}$ 570 disorders, for which age is both negatively (direct) and positively (indirect) associated with 571 symptom frequency reporting. Older persons tend to report fewer symptoms of Affect $/ \mathrm{mood}$ 572 disorders (direct), unless they suffer from chronic health conditions and/or nervous system 573 disorders (indirect). Past $\mathrm{Hg}$ exposure mediated the contribution of age for all clusters, except for 574 Gross motor disorders (Supplementary Figure 8, Additional File 1) and Neuro-cognitive deficits 575 (Supplementary Figure 9, Additional File 1).

\section{Discussion}

579 To our knowledge, this is the first study to link past $\mathrm{Hg}$ exposure from freshwater fish consumption 580 with clusters of current multiple coexisting symptoms. Clustering analysis enabled us to 581 characterize the various symptom profiles, which constitute the physical and/or mental translation 582 of structural phenomena. The non-random distribution of symptoms and their strong correlation in 
583 each cluster suggests a common mechanism or etiology $(10,12,66)$. Here, the six clusters, derived

584 from statistical empirical validation, reflect the involvement of different aspects of nervous system

585 dysfunction, which we classified as representing primarily Extrapyramidal impairment, Sensory

586 impairment, Cranial nerve disturbances, Gross motor impairment, Neuro-cognitive deficits, and

587 Affect/Mood disorders. The symptoms that make up these clusters are similar to those reported by

588 persons from Grassy Narrows in $2010(8,67)$ and consistent with the many descriptions of methyl

589 Hg poisoning through fish consumption (68-75).

591 Hg biomarker data, collected in Grassy Narrows First Nation between 1970 and 1997 provided a

592 unique opportunity to examine these clusters with respect to past exposure over a long-term period

593 and at various time points. The findings of longitudinal exposure, based on participants with at

594 least 10 year-based hair $\mathrm{Hg}$ measurements over the sampling period, show that long-term $\mathrm{Hg}$

595 exposure is associated with higher symptom frequency for all the clusters of nervous system 596 dysfunction, with the exception of Affect/Mood disorders. This is consistent with SEM findings 597 where Affect/Mood disorders show a significant relation only with prenatal exposure.

599 Studies on Minamata Disease have shown differences in fetal, non-fetal infantile and adult $\mathrm{Hg}$

600 damage to the brain (76). In the present study, the large majority of participants experienced both

601 prenatal and postnatal exposure. The mediated contribution of prenatal exposure on symptom

602 clusters through childhood exposure, observed in most SEMs, suggests that their independent

603 contributions are difficult to assess.

604 
605 SEM provided the opportunity to simultaneously examine covariance, mediation and moderation

606 between variables through a domino effect of successive pathways from past exposure to current

607 symptoms. The Hg exposure latent variable, which groups different periods of exposure (prenatal

$608 \mathrm{Hg}$, childhood $\mathrm{Hg}$ and hair $\mathrm{Hg} \geq 5 \mu \mathrm{g} / \mathrm{g}$ at least once), enabled us to examine their combined

609 contributions. Latent $\mathrm{Hg}$ exposure variables have been used in other studies. Choi et al. (23)

610 showed that the grouped $\mathrm{Hg}$ exposure variable, including current $\mathrm{Hg}$ nail and blood concentrations

611 and hair $\mathrm{Hg}$ concentration 7 years previously, was associated with adverse cardiovascular

612 outcomes in Faroese whaling men. In a study by Grandjean and co-authors (77), the combined

613 prenatal and childhood $\mathrm{Hg}$ exposures were negatively related to children's neurobehavioral

614 outcomes. In the present study, the combined past $\mathrm{Hg}$ exposures are directly and indirectly,

615 associated with all clusters.

617 Independent $\mathrm{Hg}$ exposures may provide insight into the relative importance of exposure at different 618 time periods. Prenatal exposure is directly associated with Affect/mood disorders, while for other 619 clusters, its contribution is mediated by childhood exposure. Fetal Minamata patients present with 620 psychiatric disorders (Harada, 1964 cited in (78). A re-analysis of 1971 data from Minamata 621 patients showed that psychiatric symptoms peaked at 20 years of age (78). This may be similar to 622 the present study where young adults ( $\leq 29$ years of age) report a higher frequency of altered mood 623 symptoms. The importance of prenatal and childhood Hg exposure has been raised by many 624 authors $(25,79)$. Children are more vulnerable to toxic exposure than adults because their brains 625 are in a state of rapid growth, with relatively higher absorption rates to body weight, and their body 626 systems are not prepared to properly metabolize, detoxify, and excrete toxic substances (80-82). 
628 Although the GN-CHA did not include the age of onset of symptoms, the association between past

629 exposure and later-life symptoms raises the issue of delayed and/or progressive neurotoxicity.

630 Delayed neurotoxicity was reported in 13-year-old monkeys, treated with methyl $\mathrm{Hg}$ from birth to

631 seven years of age (83). A silent latency period for methyl $\mathrm{Hg}$ toxicity has been proposed using

632 examples from the Minamata and Iraq disasters (84). Newland and co-authors (85) discuss

633 mechanisms by which neuronal development may have long-lasting behavioral consequences that

634 appear in adulthood and, in some cases, may not appear until aging.

636 The FNRHS 2008/2010 included few nervous system disorders in their list of diagnosed health

637 conditions (27). The GN-CHA added a series of neurologic disorders which share some of the

638 signs and symptoms of $\mathrm{Hg}$ poisoning. These disorders mediate the relation between latent $\mathrm{Hg}$

639 exposure and all symptom clusters and between childhood exposure and Sensory impairment,

640 Gross Motor impairment and Neuro-cognitive deficits.

641

642 In Canada, chronic health conditions are disproportionately higher among Indigenous

643 communities compared to the non-Indigenous population (86). The most commonly reported

644 chronic health conditions in the GN-CHA are similar to other First Nation communities across

645 Canada: high blood pressure, allergies, arthritis, diabetes, and chronic back pain (27). Results of 646 the SEM show the expected associations of having at least one chronic health condition with age 647 and obesity, with women presenting a higher prevalence compared to men. It is noteworthy that 648 the highest direct contribution to all symptom clusters is having at least one chronic health 649 condition and/or having at least one nervous system disorder. 
651 SEM remains one of the best approaches to assess simultaneously direct and indirect associations

652 by investigating all relevant regression pathways. Although it cannot prove causation between $\mathrm{Hg}$

653 exposure and clusters, the positive relations between past $\mathrm{Hg}$ exposure and current symptoms

654 frequency reveal links that are not explainable by reverse causation. The concordant results in

655 longitudinal MEM support these findings. Our findings are consistent with follow-up studies of

656 persons that had been affected by Hg pollution from the Chisso Company in Minamata, decades

657 after the company had halted the dumping of methyl $\mathrm{Hg}$ into the bay $(74,87-89)$. The Japanese

658 studies compared persons who had lived in polluted and non-polluted regions since they did not

659 have actual measures of $\mathrm{Hg}$ exposure for the individuals who were evaluated.

661 Some limitations need to be considered in interpreting the present results. The study reposes on 662 self-reported questionnaire data from the GN-CHA, raising the question of recall bias, and under663 or over-reporting. To offset these limitations, the Cronbach alpha and CFA confirmed the construct 664 reliability of self-reported symptom frequency. Reported diagnosed health conditions and nervous 665 system disorders reflect whether a person has consulted a health professional who has made the 666 diagnosis of this condition, as well as the accuracy of the diagnosis. Further studies would benefit 667 from clinical assessments in relation to historic $\mathrm{Hg}$ exposure.

669 A further limitation is with respect to $\mathrm{Hg}$ biomarkers obtained from a government monitoring 670 program (3). Sampling was not carried out regularly and samples were not collected yearly from 671 everyone, resulting in many missing values. Moreover, there are seasonal and yearly differences 672 in fish consumption frequency $(3,6)$. Hg exposure imprecision is also associated with blood and 673 hair measurements over the sampling years, notably laboratory measurement imprecision and 
674 biological variation (90). Ideally, one would like continuous $\mathrm{Hg}$ biomarker measurements over all

675 participants' lifetime, but this is not possible. To address the challenges posed by the biomarker

676 database, for the longitudinal MEMs, we limited the analyses to persons with a minimum of 10

677 hair Hg measurements, representing exposure for 10 years or more. For the SEMs, the estimated

678 umbilical cord and childhood $\mathrm{Hg}$ values were validated, and we used latent variables of $\mathrm{Hg}$

679 exposure to manage residual error terms between variables.

680

681 Finally, the Grassy Narrows Hg disaster began in 1962 and after 1970, fish Hg concentration

682 decreased over time and fish consumption, paralleled by a decrease in biomarker $\mathrm{Hg}$

683 concentrations. The association of $\mathrm{Hg}$ exposure in the models may be partially masked by age.

684 The inverse relation between year of birth and $\mathrm{Hg}$ exposure makes age an ambiguous variable. It

685 is a risk factor for the symptom clusters, covaries with $\mathrm{Hg}$ exposure, but is not a consequence of

686 Hg exposure.

687

689 Conclusions

690

691 Since the disaster, Grassy Narrows First Nation has expressed concern about the high rate of 692 symptoms of nervous system dysfunction in their community. This is the first study to demonstrate

693 links between retrospective Hg exposure and current coexisting symptoms. Given the complexity

694 of the interrelations between the various determinants of chronic health problems in this and other

695 First Nation communities, LMEM and SEM methods enabled us to trace direct and/or indirect

696 routes of potential "causal impact" manifest after many years of $\mathrm{Hg}$ exposure. 
699 Declarations

701 Ethics approval and consent to participate

702 Ethics approval for the GN-CHA was obtained from the Manitoulin Anishinaabek Research 703 Review Committee (MARRC), who issued an Ethics Certificate on September 1, 2016. Informed

704 consent forms were signed by all participants. Consent included survey participation and the 705 linking of the information from the GN-CHA to data obtained from previous surveillance programs 706 and/or studies of $\mathrm{Hg}$ exposure. Ethics approval for the present study was obtained from the 707 Université du Québec à Montréal (2016_e_1350) and Health Canada Research Ethics Board (REB 708 2017-0006).

710 Consent for publication

711 All participants provided consent for publication. The present study was presented to Grassy

712 Narrows' Chief and Council of, who approved the manuscript for publication on May 12, 2021.

714 Availability of data and materials

715 Archived mercury biomarker data was obtained from the First Nations and Inuit Health Branch 716 (FNIHB) of the Ministry of Indigenous Services Canada, at the request of Grassy Narrows First

717 Nation. The datasets generated and analysed in the present study are the property of Grassy 718 Narrows First Nation. Permission for use of the data lies with Grassy Narrows Chief and Council. 
721 The authors declare that they have no competing interests

\section{$723 \quad$ Funding}

724 The GN-CHA received financial support from Health Canada and the Ontario Ministry of Health

725 and Long-Term Care and technical support from these ministries and the Ontario Agency for

726 Health Protection and Promotion, the Ontario Ministry of Indigenous Relations and Reconciliation

727 and the Northwestern Health Unit of Ontario. The present study was funded by the Canadian

728 Institutes for Health Research (\#152882).

\section{Authors contributions}

731 AP created the database, determined the statistical approaches and performed the analyses. She

732 co-wrote the manuscript with DM. JDS is the initiator and organizer of the GN-CHA survey. She

733 provided input for data interpretation. MF participated in the analyses and dissemination of the

734 GN-CHA. She participated in the writing and editing of the manuscript. TSL provided the

735 neurological interpretation of the symptom clusters and verified the manuscript. DM was invited

736 by Grassy Narrows First Nation as scientific advisor for the GN-CHA. She was responsible for

737 over-seeing the fieldwork, analyzing the data and preparing the reports. She is principal

738 investigator on the present research. All authors read and approved the final manuscript

740 Acknowledgements

741 We thank all of the people of Grassy Narrows who organized and carried out the Grassy Narrows

742 Community Health Assessment (CHA): the community advisory committee, the fieldwork 
743 coordinators and the surveyors. A special thank you to the people of Grassy Narrows who

744 participated in the CHA and agreed to share their biomarker data with us.

745

746

Table 4. Characteristics of symptom clusters

747

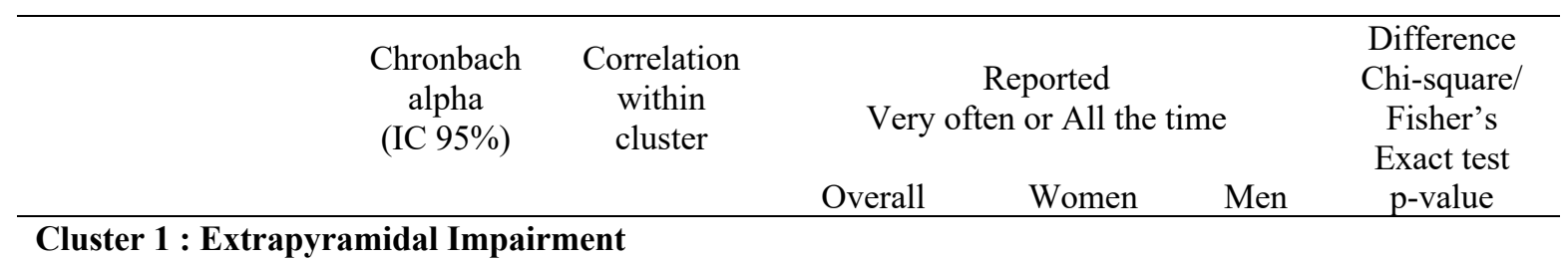

$0.91(0.90-0.92)$

\begin{tabular}{|c|c|c|c|c|c|}
\hline Pain in arms & 0.80 & $\begin{array}{c}44 \\
(11.5 \%)\end{array}$ & $\begin{array}{c}28 \\
(13.7 \%)\end{array}$ & $\begin{array}{c}16 \\
(9.0 \%)\end{array}$ & 0.19 \\
\hline Pain in legs & 0.80 & $\begin{array}{c}75 \\
(19.6 \%)\end{array}$ & $\begin{array}{c}52 \\
(25.2 \%)\end{array}$ & $\begin{array}{c}23 \\
(13.1 \%)\end{array}$ & 0.003 \\
\hline Drop things & 0.75 & $\begin{array}{c}53 \\
(13.9 \%)\end{array}$ & $\begin{array}{c}37 \\
(17.9 \%)\end{array}$ & $\begin{array}{c}16 \\
(9.2 \%)\end{array}$ & 0.017 \\
\hline Feet tremors & 0.77 & $\begin{array}{c}25 \\
(6.6 \%)\end{array}$ & $\begin{array}{c}13 \\
(6.4 \%)\end{array}$ & $\begin{array}{c}12 \\
(6.8 \%)\end{array}$ & 0.873 \\
\hline Stiff shoulders & 0.75 & $\begin{array}{c}51 \\
(13.4 \%)\end{array}$ & $\begin{array}{c}33 \\
(16.1 \%)\end{array}$ & $\begin{array}{c}18 \\
(10.2 \%)\end{array}$ & 0.099 \\
\hline Burning feet & 0.75 & $\begin{array}{c}48 \\
(12.7 \%)\end{array}$ & $\begin{array}{c}34 \\
(16.8 \%)\end{array}$ & $\begin{array}{c}14 \\
(8.0 \%)\end{array}$ & 0.01 \\
\hline Stumble & 0.78 & $\begin{array}{c}39 \\
(10.1 \%)\end{array}$ & $\begin{array}{c}21 \\
(10.2 \%)\end{array}$ & $\begin{array}{c}18 \\
(10.1 \%)\end{array}$ & 0.992 \\
\hline Stop or freeze & 0.74 & $\begin{array}{c}14 \\
(3.7 \%)\end{array}$ & $\begin{array}{c}10 \\
(4.9 \%)\end{array}$ & $\begin{array}{c}4 \\
(2.3 \%)\end{array}$ & 0.275 \\
\hline Fall & 0.75 & 19 & 14 & 5 & 0.099 \\
\hline
\end{tabular}


Cluster 2: Sensory Impairment

$$
0.94(0.93-0.95)
$$

Numbness in hands

Numbness in feet

Dull feeling in hands

Dull feeling in feet

Tingling in hands

Tingling in feet
0.88

0.89

\begin{tabular}{r|rr}
$(13.8 \%)$ & $(16.5 \%) \quad(10.7 \%)$ \\
\hline
\end{tabular}

\section{Cluster 3 : Cranial nerve disturbances}

$$
0.85(0.83-0.88)
$$

\begin{tabular}{lcc|ccc} 
Loss of taste & 0.85 & 23 & 17 & 6 & 0.053 \\
& & $(6.0 \%)$ & $(8.3 \%)$ & $(3.4 \%)$ \\
Loss of smell & 0.82 & 26 & 16 & 10 & 0.423 \\
& & $(6.8 \%)$ & $(7.8 \%)$ & $(5.7 \%)$ & 0.068 \\
Difficulty swallowing & 0.81 & 33 & 23 & $(10 \%)$ \\
\end{tabular}




\begin{tabular}{lcc|ccc}
\hline Tingling around mouth & 0.73 & 24 & 17 & 7( & 0.094 \\
& & $(6.3 \%)$ & $(8.3 \%)$ & $4.0 \%)$ \\
Choking & 0.81 & 15 & 12 & 3 & 0.061 \\
& & $(3.9 \%)$ & $(5.8 \%)$ & $(1.7 \%)$
\end{tabular}

Cluster 4: Gross motor impairment

$0.89(0.88-0.91)$

Difficulty walking 5 minutes

0.91

without rest

Difficulty climbing stairs

0.92

38

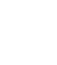

$\begin{array}{lll}29 & 9 & 0.004\end{array}$

$(9.9 \%) \quad(14.0 \%) \quad(5.1 \%)$

\begin{tabular}{lcc|ccc} 
Difficulty climbing stairs & 0.92 & 47 & 37 & 10 & 0 \\
& & $(12.3 \%)$ & $(17.8 \%)$ & $(5.68 \%)$ \\
Trouble lifting & 0.89 & 77 & 50 & 27 & 0.025 \\
& & $(20.3 \%)$ & $(24.5 \%)$ & $(15.3 \%)$ \\
Trouble lifting 10 lbs & 0.82 & 36 & 32 & 4 & 0
\end{tabular}

\section{Cluster 5: Neuro-cognitive deficits}

$$
0.82(0.79-0.85)
$$

\begin{tabular}{|c|c|c|c|c|c|}
\hline \multirow[t]{2}{*}{ Trouble hearing } & 0.74 & 48 & 28 & 20 & 0.485 \\
\hline & & $(12.5 \%)$ & $(13.6 \%)$ & $(11.2 \%)$ & \\
\hline Difficulty having his/her speech & 0.77 & 27 & 17 & 10 & 0.424 \\
\hline understood & & $(7.1 \%)$ & $(8.3 \%)$ & $(5.7 \%)$ & \\
\hline \multirow[t]{2}{*}{ Difficulty pronouncing words } & 0.77 & 39 & 21 & 18 & 0.992 \\
\hline & & $(10.1 \%)$ & $(10.1 \%)$ & $(10.1 \%)$ & \\
\hline \multirow[t]{2}{*}{ Forget where to put things } & 0.79 & 76 & 50 & 26 & 0.018 \\
\hline & & $(19.8 \%)$ & $(24.3 \%)$ & $(14.7 \%)$ & \\
\hline \multirow[t]{2}{*}{ Forget doing things } & 0.8 & 35 & 23 & 12 & 0.158 \\
\hline & & $(9.1 \%)$ & $(11.1 \%)$ & $(6.8 \%)$ & \\
\hline
\end{tabular}


Cluster 6: Affect/Mood disorders

$$
0.9(0.89-0.91)
$$

\begin{tabular}{|c|c|c|c|c|c|}
\hline \multirow[t]{2}{*}{ Anxious } & 0.81 & 57 & 39 & 18 & 0.016 \\
\hline & & $(14.9 \%)$ & $(18.9 \%)$ & $(10.2 \%)$ & \\
\hline \multirow[t]{2}{*}{ Tired } & 0.81 & 111 & 74 & 37 & 0.001 \\
\hline & & $(28.9 \%)$ & $(35.9 \%)$ & $(20.9 \%)$ & \\
\hline \multirow[t]{2}{*}{ Irritable } & 0.81 & 50 & 36 & 14 & 0.006 \\
\hline & & $(13.1 \%)$ & $(17.5 \%)$ & $(7.9 \%)$ & \\
\hline \multirow[t]{2}{*}{ Depressed } & 0.77 & 58 & 36 & 22 & 0.151 \\
\hline & & $(15.4 \%)$ & $(17.9 \%)$ & $(12.6 \%)$ & \\
\hline \multirow[t]{2}{*}{ Difficulty concentrating } & 0.78 & 60 & 39 & 21 & 0.054 \\
\hline & & $(15.9 \%)$ & $(19.2 \%)$ & $(12.0 \%)$ & \\
\hline \multirow[t]{2}{*}{ Wake up at night } & 0.77 & 141 & 86 & 55 & 0.037 \\
\hline & & $(36.8 \%)$ & $(41.6 \%)$ & $(31.2 \%)$ & \\
\hline \multirow[t]{2}{*}{ Trouble falling asleep } & 0.75 & 138 & 74 & 64 & 0.901 \\
\hline & & $(36.0 \%)$ & $(35.8 \%)$ & $(36.4 \%)$ & \\
\hline \multirow[t]{2}{*}{ Doing nothing } & 0.72 & 65 & 45 & 20 & 0.005 \\
\hline & & $(17.0 \%)$ & $(21.9 \%)$ & $(11.2 \%)$ & \\
\hline
\end{tabular}

748

749

750 


\section{$751 \quad$ Figure captions}

752 Figure 1. Breakdown of GN-CHA participants with Hg biomarker measurements

753

754 Figure 2. Distribution of measured Hg biomarkers over time

755

2a. Hair Hg $(\mu \mathrm{g} / \mathrm{g}) 1970$ - $1997(\mathrm{n}=208)$

2b. Umbilical cord blood Hg $(\mu \mathrm{g} / \mathrm{L}) 1970-1992(\mathrm{n}=211)$

757

758 Figure 3. Distribution of mean hair $\mathrm{Hg}(\mu \mathrm{g} / \mathrm{g})$ at 10 years of age with respect to childhood fish 759 consumption: $\geq$ several times a month $(n=76)$ and less $(n=42)$.

760 Note: The fitted line represents second order polynomial (quadratic), with a shaded confidence 761 band.

762

763 Figure 4. Graphic outputs for cluster decision

4a. Plot of the aggregation levels of symptom clusters

765

$4 \mathrm{~b}$. Plot of stability of the partitions of clusters

766

4c. Plot of dispersion of the adjusted Rand index

767

768 Figure 5. SEM path diagram linking retrospective latent $\mathrm{Hg}$ exposure and covariates to the latent 769 symptoms cluster variable for Extrapyramidal impairment.

770

771 
772 Abbreviations: $\chi 2 / \mathrm{df}$ : Chi-square divided by the degrees of freedom ( $\chi 2 / \mathrm{df})$, CFI: Comparative Fit

773 Index, TLI: Tucker Lewis Index, RMSEA: Root Mean Square Error of Approximation, SRMR:

774 Standardized Root Mean Square Residual.

775

776 Figure 6. SEM path diagram linking retrospective $\mathrm{Hg}$ exposure parameters (prenatal and 777 childhood Hg exposure, and having had $\geq 5 \mu \mathrm{g} / \mathrm{g}$ hair $\mathrm{Hg}$ at least once between 1970 and 1997) 778 and covariates to the latent symptoms cluster variable for Extrapyramidal impairment.

780 Abbreviations: $\chi 2 / \mathrm{df}$ : Chi-square divided by the degrees of freedom $(\chi 2 / \mathrm{df})$, CFI: Comparative Fit 781 Index, TLI: Tucker Lewis Index, RMSEA: Root Mean Square Error of Approximation, SRMR: 782 Standardized Root Mean Square Residual.

784 Figure 7. SEM standardized path coefficients for direct and indirect contributions of latent $\mathrm{Hg}$ and 785 covariates on the symptom latent variable for each cluster

787 Figure 8. SEM standardized path coefficients for direct and indirect contributions of prenatal, 788 childhood and $\geq 5 \mu \mathrm{g} / \mathrm{g}$ hair $\mathrm{Hg}(1970-1997)$ and covariates on the symptom latent variable for 789 each cluster 
794 1.Rudd JWM, Turner MA, Furutani A. The English-Wabigoon River system: I. A synthesis of 795 recent research with a view towards mercury amelioration. Canadian Journal of Fisheries and 796 Aquatic Sciences. 1983;40(12):2206-17.

797 2.Etkin D. Disaster Theory: An Interdisciplinary Approach to Concepts and Causes. Disaster 798 Theory: An Interdisciplinary Approach to Concepts and Causes: Elsevier, Butterworth799 Heinemann; 2016. p. 138-42.

800 3. Wheatley B, Paradis S. Exposure of Canadian aboriginal peoples to methylmercury. Water, Air, 801 and Soil Pollution. 1995;80(1):3-11.

802 4.Wheatley B, Paradis S, Lassonde M, Giguere MF, Tanguay S. Exposure Patterns and Long Term 803 Sequelae on Adults and Children in Two Canadian Indigenous Communities Exposed to 804 Methylmercury. Water, Air and Soil Pollution. 1997;97(1-2):63-73.

805 5.Neff MR, Bhavsar SP, Arhonditsis GB, Fletcher R, Jackson DA. Long-term changes in fish 806 mercury levels in the historically impacted English-Wabigoon River system (Canada). J Environ 807 Monit. 2012;14(9):2327-37.

808 6.Philibert A, Fillion M, Mergler D. Mercury exposure and premature mortality in the Grassy 809 Narrows First Nation community: a retrospective longitudinal study. The Lancet Planetary Health. $810 \quad 2020 ; 4(4): \mathrm{e} 141-\mathrm{e} 8$.

811 7.Harada M, Hanada M, Tajiri M, Inoue Y, Hotta N, Fujino T, et al. Mercury Pollution in First 812 Nations Groups in Ontario, Canada: 35 years of Canadian Minamata Disease (English translation).

813 Journal of Minamata Studies. 2011;3:3-30. 
814 8.Takaoka S, Fujino T, Hotta N, Ueda K, Hanada M, Tajiri M, et al. Signs and symptoms of

815 methylmercury contamination in a First Nations community in Northwestern Ontario, Canada. Sci

816 Total Environ. 2014;468-469:950-7.

817 9.Eto K, Marumoto M, Takeya M. The pathology of methylmercury poisoning (Minamata

818 disease): The 50th Anniversary of Japanese Society of Neuropathology. Neuropathology.

$8192010 ; 30(5): 471-9$.

820 10.Miaskowski C, Dodd M, Lee K. Symptom clusters: the new frontier in symptom management

821 research. J Natl Cancer Inst Monogr. 2004;32:17-21.

822 11.Skerman HM, Yates PM, Battistutta D. Multivariate methods to identify cancer-related 823 symptom clusters. Res Nurs Health. 2009;32(3):345-60.

824 12.Barsevick AM, Whitmer K, Nail LM, Beck SL, Dudley WN. Symptom cluster research: 825 conceptual, design, measurement, and analysis issues. J Pain Symptom Manage. 2006;31(1):8582695.

827 13.Aktas A, Walsh D, Rybicki L. Symptom clusters: myth or reality? Palliat Med. 2010;24(4):373$828 \quad 85$.

829 14.Miaskowski C. Future Directions in Symptom Cluster Research. Semin Oncol Nurs. $830 \quad 2016 ; 32(4): 405-15$.

831 15.Miaskowski C, Barsevick A, Berger A, Casagrande R, Grady PA, Jacobsen P, et al. Advancing

832 Symptom Science Through Symptom Cluster Research: Expert Panel Proceedings and 833 Recommendations. J Natl Cancer Inst. 2017;109(4).

834 16.Weihe P, Grandjean P, Debes F, White R. Health implications for Faroe islanders of heavy 835 metals and PCBs from pilot whales. Sci Total Environ. 1996;186(1-2):141-8. 
836 17.Budtz-Jørgensen E, Keiding N, Grandjean P, Weihe P. Estimation of health effects of prenatal

837 methylmercury exposure using structural equation models. Environ Health. 2002;1(1):1-2.

838 18.Budtz-Jørgensen E, Grandjean P, Jørgensen PJ, Weihe P, Keiding N. Association between

839 mercury concentrations in blood and hair in methylmercury-exposed subjects at different ages.

840 Environ Res. 2004;95(3):385-93.

841 19.Sánchez BN, Budtz-Jørgensen E, Ryan LM, Hu H. Structural Equation Models. Journal of the 842 American Statistical Association. 2005;100(472):1443-55.

843 20.Grandjean P, Budtz-Jørgensen E, Jørgensen PJ, Weihe P. Umbilical cord mercury 844 concentration as biomarker of prenatal exposure to methylmercury. Environ Health Perspect. $845 \quad 2005 ; 113(7): 905-8$.

846 21.Debes F, Budtz-Jorgensen E, Weihe P, White RF, Grandjean P. Impact of prenatal 847 methylmercury exposure on neurobehavioral function at age 14 years. Neurotoxicol Teratol. $848 \quad 2006 ; 28(5): 536-47$.

849 22.Choi AL, Budtz-Jorgensen E, Jorgensen PJ, Steuerwald U, Debes F, Weihe P, et al. Selenium 850 as a potential protective factor against mercury developmental neurotoxicity. Environ Res. $8512008 ; 107(1): 45-52$.

852 23.Choi AL, Weihe P, Budtz-Jørgensen E, Jørgensen PJ, Salonen JT, Tuomainen TP, et al. 853 Methylmercury exposure and adverse cardiovascular effects in Faroese whaling men. Environ 854 Health Perspect. 2009;117(3):367-72.

855 24.Grandjean P, Weihe P, Nielsen F, Heinzow B, Debes F, Budtz-Jorgensen E. Neurobehavioral 856 deficits at age 7 years associated with prenatal exposure to toxicants from maternal seafood diet. 857 Neurotoxicol Teratol. 2012;34(4):466-72. 
858 25.Grandjean P, Landrigan PJ. Neurobehavioural effects of developmental toxicity. Lancet

859 Neurol. 2014;13(3):330-8.

860 26.Debes F, Weihe P, Grandjean P. Cognitive deficits at age 22 years associated with prenatal 861 exposure to methylmercury. Cortex. 2016;74:358-69.

862 27.FNIGC. First Nations Regional Health Survey (RHS) 2008/10: National report on adults, youth 863 and children living in First Nations communities. Ottawa, Canada: The First Nations Information 864 Governance Centre/ Le Centre de la Gouvernance de L’information des Premères Nations; 2012.

865 28.Farant JP, Brissette D, Moncion L, Bigras L, Chartrand A. Improved cold-vapor atomic 866 absorption technique for the microdetermination of total and inorganic mercury in biological 867 samples. Journal of Analytical Toxicology. 1981;5(1):47-51.

868 29.Magos L. Selective atomic-absorption determination of inorganic mercury and methylmercury 869 in undigested biological samples. Analyst. 1971;96(149):847-53.

870 30.Chavent M, Kuentz V, Liquet B, Saracco L. ClustOfVar: An R Package for the Clustering of 871 Variables2011 December 01, 2011:[arXiv:1112.0295 p.]. Available from:

872 https://ui.adsabs.harvard.edu/abs/2011arXiv1112.0295C.

873 31.Chavent M, Genuer R, Kuentz-Simonet V, Liquet B, Saracco J. ClustOfVar : an R package for 874 dimension reduction via clustering of variables. Application in supervised classification and 875 variable selection in gene expressions data. Statistical Methods for (post)-Genomics Data 876 (SMPGD 2013); 2013-01-24; Netherlands2013.

877 32.Kuentz Simonet V, Lyser S, Candau J, Deuffic P. ClustOfVar-based approach for unsupervised 878 learning: Reading of synthetic variables with sociological data. Electronic Journal of Applied 879 Statistical Analysis. 2015;8(2):170-97. 
880 33.Kuentz-Simonet V, Labenne A, Rambonilaza T. Using ClustOfVar to Construct Quality of Life

881 Indicators for Vulnerability Assessment Municipality Trajectories in Southwest France from 1999

882 to 2009. Social Indicators Research. 2017;131(3):973-97.

883 34.Xie B, Pan W, Shen X. Penalized model-based clustering with cluster-specific diagonal

884 covariance matrices and grouped variables. Electronic journal of statistics. 2008;2:168-212.

885 35.Hu Lt, Bentler PM. Cutoff criteria for fit indexes in covariance structure analysis: Conventional

886 criteria versus new alternatives. Structural Equation Modeling: A Multidisciplinary Journal.

$887 \quad$ 1999;6(1):1-55.

888 36.Enders CK, Bandalos DL. The Relative Performance of Full Information Maximum Likelihood

889 Estimation for Missing Data in Structural Equation Models. Structural Equation Modeling: A

890 Multidisciplinary Journal. 2001;8(3):430-57.

891 37.Schreiber JB, Nora A, Stage FK, Barlow EA, King J. Reporting Structural Equation Modeling

892 and Confirmatory Factor Analysis Results: A Review. The Journal of Educational Research. $893 \quad 2006 ; 99(6): 323-38$.

894 38.Hooper D, Coughlan J, Mullen MR, editors. Structural equation modelling: guidelines for 895 determining model fit2008.

896 39.Rosseel Y. lavaan: An R Package for Structural Equation Modeling. 2012. 2012;48(2):36.

897 40.Cronbach LJ. Coefficient alpha and the internal structure of tests. Psychometrika. $898 \quad 1951 ; 16(3): 297-334$.

899 41.Tavakol M, Dennick R. Making sense of Cronbach's alpha. International journal of medical 900 education. 2011;2:53-5.

901 42.Taber KS. The Use of Cronbach's Alpha When Developing and Reporting Research 902 Instruments in Science Education. Research in Science Education. 2018;48(6):1273-96. 
903 43.Gibbons RD, Hedeker D, DuToit S. Advances in analysis of longitudinal data. Annual review

904 of clinical psychology. 2010;6:79-107.

905 44.Hedeker D, Gibbons RD, Waternaux C. Sample size estimation for longitudinal designs with

906 attrition: comparing time-related contrasts between two groups. Journal of Educational and

907 Behavioral Statistics. 1999;24(1):70-93.

908 45.Faul F, Erdfelder E, Buchner A, Lang A-G. Statistical power analyses using G*Power 3.1: Tests

909 for correlation and regression analyses. Behavior Research Methods. 2009;41(4):1149-60.

910 46.Faul F, Erdfelder E, Buchner A, Lang A. G* Power Version 3.1. 7 [computer software].

911 Uiversität Kiel, Germany. 2013.

912 47.Kyonka EGE. Tutorial: Small-N Power Analysis. Perspectives on behavior science.

$9132018 ; 42(1): 133-52$.

914 48.National Research Council Committee on the Toxicological Effects of M. Toxicological

915 Effects of Methylmercury. Washington (DC): National Academies Press (US)

916 Copyright 2000 by the National Academy of Sciences. All rights reserved.; 2000.

917 49.Bollen KA. Latent Variables in Psychology and the Social Sciences. Annual Review of 918 Psychology. 2002;53(1):605-34.

919 50.MacCallum RC, Austin JT. Applications of Structural Equation Modeling in Psychological 920 Research. Annual Review of Psychology. 2000;51(1):201-26.

921 51.Mogensen UB, Grandjean P, Heilmann C, Nielsen F, Weihe P, Budtz-Jørgensen E. Structural 922 equation modeling of immunotoxicity associated with exposure to perfluorinated alkylates. 923 Environ Health. 2015;14:47.

924 52.Schumacker RE, Lomax RG. A beginner's guide to structural equation modeling: psychology 925 press; 2004. 
926 53.Shook-Sa BE, Chen DG, Zhou H. Using Structural Equation Modeling to Assess the Links

927 between Tobacco Smoke Exposure, Volatile Organic Compounds, and Respiratory Function for

928 Adolescents Aged 6 to 18 in the United States. Int J Environ Res Public Health. 2017;14(10).

929 54.Wang IE, Rhemtulla M. Power Analysis for Parameter Estimation in Structural Equation

930 Modeling: A Discussion and Tutorial. 2021.

931 55.Satorra A, Saris W. Power of the likelihood ratio test in covariance structure analysis.

932 Psychometrika. 1985;50(1):83-90.

933 56.MacCallum RC, Browne MW, Cai L. Testing differences between nested covariance structure

934 models: Power analysis and null hypotheses. Psychol Methods. 11. United States: (2006 APA, 935 all rights reserved). 2006. p. 19-35.

936 57.MacCallum RC, Browne MW, Sugawara HM. Power analysis and determination of sample size 937 for covariance structure modeling. Psychological Methods. 1996;1(2):130-49.

938 58.Moshagen M, Erdfelder E. A New Strategy for Testing Structural Equation Models. Structural 939 Equation Modeling: A Multidisciplinary Journal. 2016;23(1):54-60.

940 59.Suttorp MM, Siegerink B, Jager KJ, Zoccali C, Dekker FW. Graphical presentation of 941 confounding in directed acyclic graphs. Nephrol Dial Transplant. 2015;30(9):1418-23.

942 60.Ferguson KD, McCann M, Katikireddi SV, Thomson H, Green MJ, Smith DJ, et al. Evidence

943 synthesis for constructing directed acyclic graphs (ESC-DAGs): a novel and systematic method 944 for building directed acyclic graphs. International Journal of Epidemiology. 2019;49(1):322-9.

945 61.Textor J, van der Zander B, Gilthorpe MS, Liskiewicz M, Ellison GT. Robust causal inference 946 using directed acyclic graphs: the R package 'dagitty'. Int J Epidemiol. 2016;45(6):1887-94. 
947 62.Tennant PWG, Murray EJ, Arnold KF, Berrie L, Fox MP, Gadd SC, et al. Use of directed 948 acyclic graphs (DAGs) to identify confounders in applied health research: review and 949 recommendations. Int J Epidemiol. 2020.

950 63.Wang YA, Rhemtulla M. Power Analysis for Parameter Estimation in Structural Equation 951 Modeling: A Discussion and Tutorial. Advances in Methods and Practices in Psychological 952 Science 2021;4(1):1-17.

953 64.Chief Moon-Riley K, Copeland JL, Metz GAS, Currie CL. The biological impacts of 954 Indigenous residential school attendance on the next generation. SSM Popul Health. $955 \quad 2019 ; 7: 100343$.

956 65.Nguyen VK. An Epidemic of Suspicion - Ebola and Violence in the DRC. N Engl J Med. $957 \quad 2019 ; 380(14): 1298-9$.

958 66.Barsevick AM. The elusive concept of the symptom cluster. Oncol Nurs Forum. $959 \quad 2007 ; 34(5): 971-80$.

960 67.Harada M, Hanada M, Tajiri M, Inoue Y, Hotta N, Takehiko F, et al. Mercury Poisoning in 961 First Nations Groups in Ontario, Canada 35 years of Minamata Disease in Canada. Journal of 962 Minamata Studies. 2011;3:3-30.

963 68.McAlpine D, Araki S. Minamata disease: an unusual neurological disorder caused by 964 contaminated fish. Lancet. 1958;2(7047):629-31.

965 69.Harada M. Minamata disease: methylmercury poisoning in Japan caused by environmental 966 pollution. Crit Rev Toxicol. 1995;25:1-24.

967 70.Ninomiya T, Ohmori H, Hashimoto K, Tsuruta K, Ekino S. Expansion of methylmercury 968 poisoning outside of Minamata: an epidemiological study on chronic methylmercury poisoning 969 outside of Minamata. Environ Res. 1995;70(1):47-50. 
970 71.Clarkson TW, Magos L. The toxicology of mercury and its chemical compounds. Crit Rev

971 Toxicol. 2006;36(8):609-62.

972 72.Ekino S, Susa M, Ninomiya T, Imamura K, Kitamura T. Minamata disease revisited: an update 973 on the acute and chronic manifestations of methyl mercury poisoning. J Neurol Sci. 2007;262(1$974 \quad 2): 131-44$.

975 73.Taber KH, Hurley RA. Mercury exposure: effects across the lifespan. J Neuropsychiatry Clin 976 Neurosci. 2008;20(4):iv-389.

977 74.Yorifuji T, Tsuda T, Takao S, Harada M. Long-term exposure to methylmercury and neurologic 978 signs in Minamata and neighboring communities. Epidemiology. 2008;19(1):3-9.

979 75.Jackson AC. Chronic Neurological Disease Due to Methylmercury Poisoning. Can J Neurol 980 Sci. 2018;45(6):620-3.

981 76.Korogi Y, Takahashi M, Okajima T, Eto K. MR findings of Minamata disease--organic 982 mercury poisoning. J Magn Reson Imaging. 1998;8(2):308-16.

983 77.Grandjean P, Weihe P, Debes F, Choi AL, Budtz-Jørgensen E. Neurotoxicity from prenatal and 984 postnatal exposure to methylmercury. Neurotoxicol Teratol. 2014;43:39-44.

985 78.Yorifuji T, Tsuda T, Inoue S, Takao S, Harada M. Long-term exposure to methylmercury and 986 psychiatric symptoms in residents of Minamata, Japan. Environ Int. 2011;37(5):907-13.

987 79.Karagas MR, Choi AL, Oken E, Horvat M, Schoeny R, Kamai E, et al. Evidence on the human 988 health effects of low-level methylmercury exposure. Environmental Health Perspectives. $989 \quad 2012 ; 120(6): 799-806$.

990 80.Landrigan PJ, Kimmel CA, Correa A, Eskenazi B. Children's health and the environment: 991 public health issues and challenges for risk assessment. Environ Health Perspect. 2004;112(2):25799265. 
993 81.Rauh VA, Horton MK, Miller RL, Whyatt RM, Perera F. Neonatology and the Environment:

994 Impact of Early Exposure to Airborne Environmental Toxicants on Infant and Child 995 Neurodevelopment. Neoreviews. 2010;11:363-9.

996 82.Heyer DB, Meredith RM. Environmental toxicology: Sensitive periods of development and 997 neurodevelopmental disorders. Neurotoxicology. 2017;58:23-41.

998 83.Rice DC. Evidence for delayed neurotoxicity produced by methylmercury. Neurotoxicology. $999 \quad 1996 ; 17(3-4): 583-96$.

1000 84.Weiss B, Clarkson TW, Simon W. Silent latency periods in methylmercury poisoning and in 1001 neurodegenerative disease. Environ Health Perspect. 2002;110 Suppl 5(Suppl 5):851-4.

1002 85.Newland MC, Reed MN, Rasmussen E. A hypothesis about how early developmental 1003 methylmercury exposure disrupts behavior in adulthood. Behavioural processes. 2015;114:41-51.

1004 86.Adelson N. The embodiment of inequity: health disparities in aboriginal Canada. Can J Public 1005 Health. 2005;96 Suppl 2(Suppl 2):S45-61.

1006 87.Ninomiya T, Imamura K, Kuwahata M, Kindaichi M, Susa M, Ekino S. Reappraisal of 1007 somatosensory disorders in methylmercury poisoning. Neurotoxicol Teratol. 2005;27(4):643-53.

1008 88.Takaoka S, Fujino T, Kawakami Y, Shigeoka SI, Yorifuji T. Survey of the Extent of the 1009 Persisting Effects of Methylmercury Pollution on the Inhabitants around the Shiranui Sea, Japan. 1010 Toxics. 2018;6(3).

1011 89.Yorifuji T, Takaoka S, Grandjean P. Accelerated functional losses in ageing congenital 1012 Minamata disease patients. Neurotoxicology and Teratology. 2018;69:49-53.

1013 90.Budtz-Jørgensen E, Keiding N, Grandjean P. Effects of exposure imprecision on estimation of 1014 the benchmark dose. Risk Anal. 2004;24(6):1689-96. 
Figures

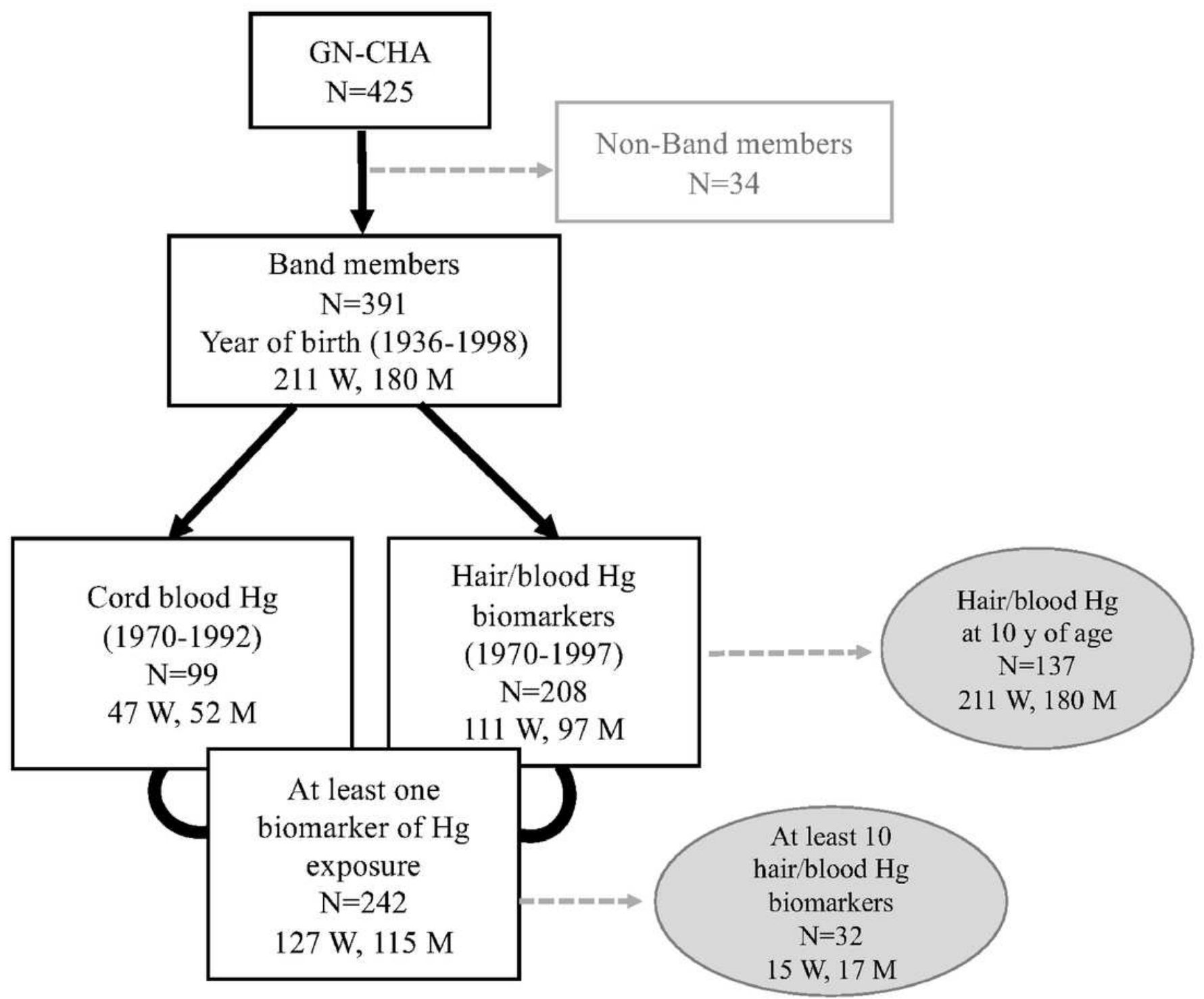

Figure 1

Breakdown of $\mathrm{GN}-\mathrm{CHA}$ participants with $\mathrm{Hg}$ biomarker measurements 

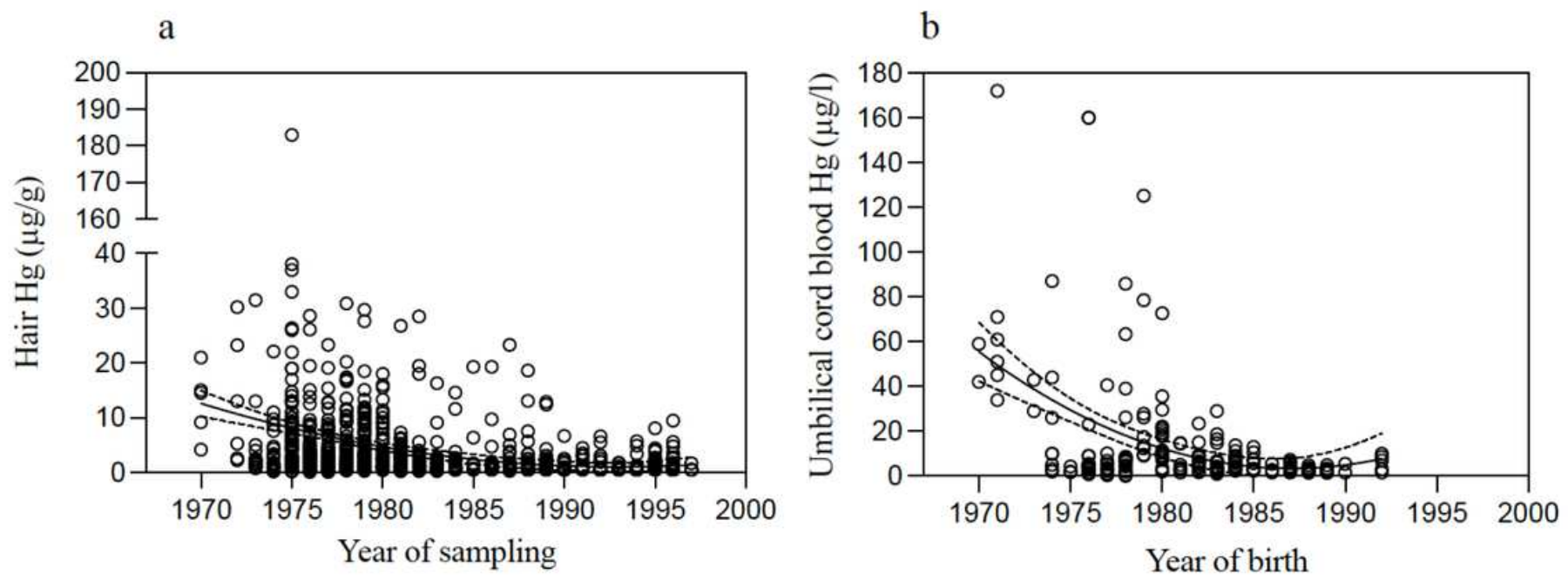

Figure 2

Distribution of measured Hg biomarkers over time 2a. Hair Hg $(\mu \mathrm{g} / \mathrm{g}) 1970$ - $1997(\mathrm{n}=208) 2 \mathrm{~b}$. Umbilical cord blood Hg $(\mu \mathrm{g} / \mathrm{L}) 1970-1992(\mathrm{n}=211)$

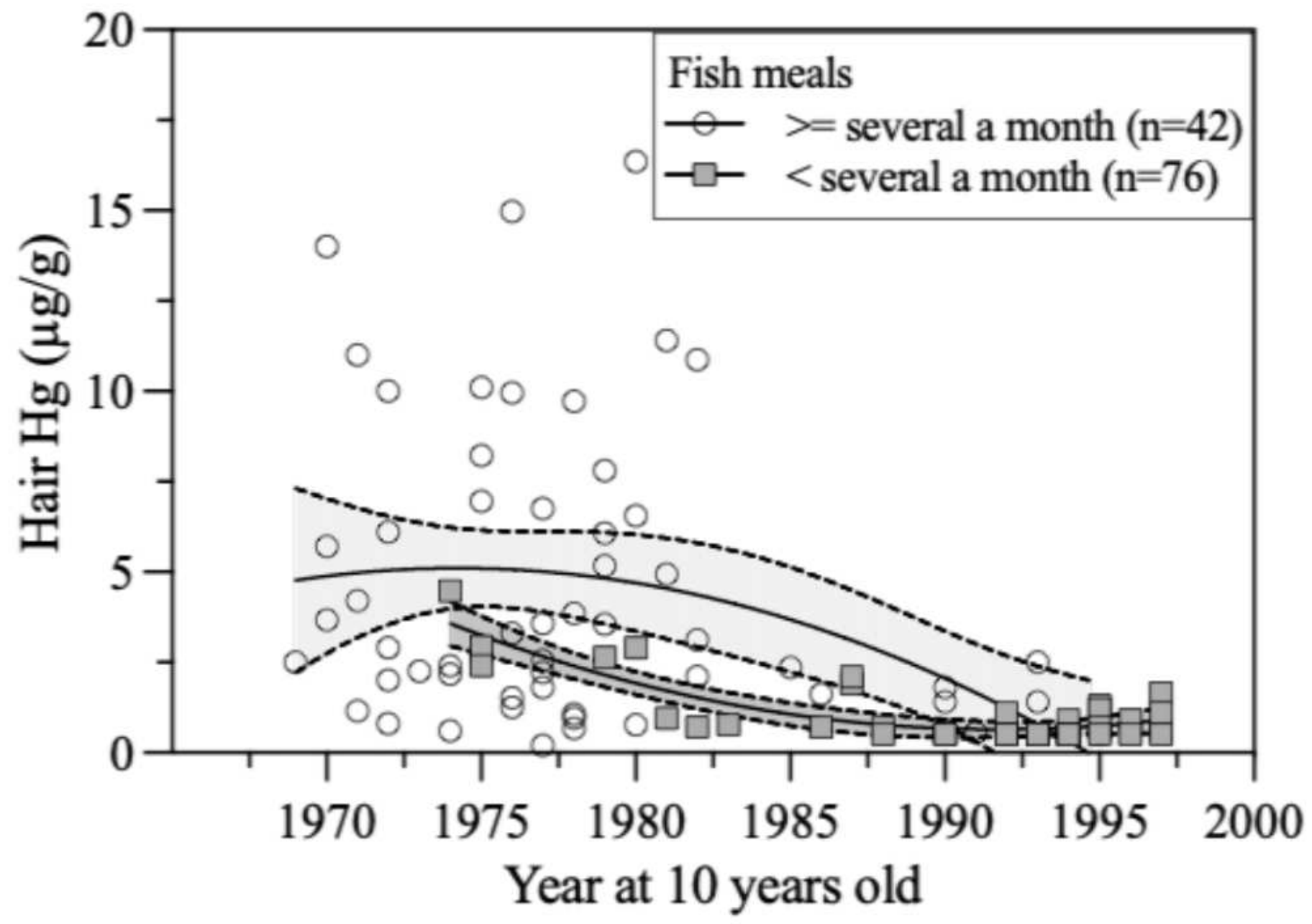


Figure 3

Distribution of mean hair $\mathrm{Hg}(\mu \mathrm{g} / \mathrm{g})$ at 10 years of age with respect to childhood fish consumption: $\geq$ several times a month $(n=76)$ and less $(n=42)$. Note: The fitted line represents second order polynomial (quadratic), with a shaded confidence band.

$\mathrm{a}$

Aggregation levels
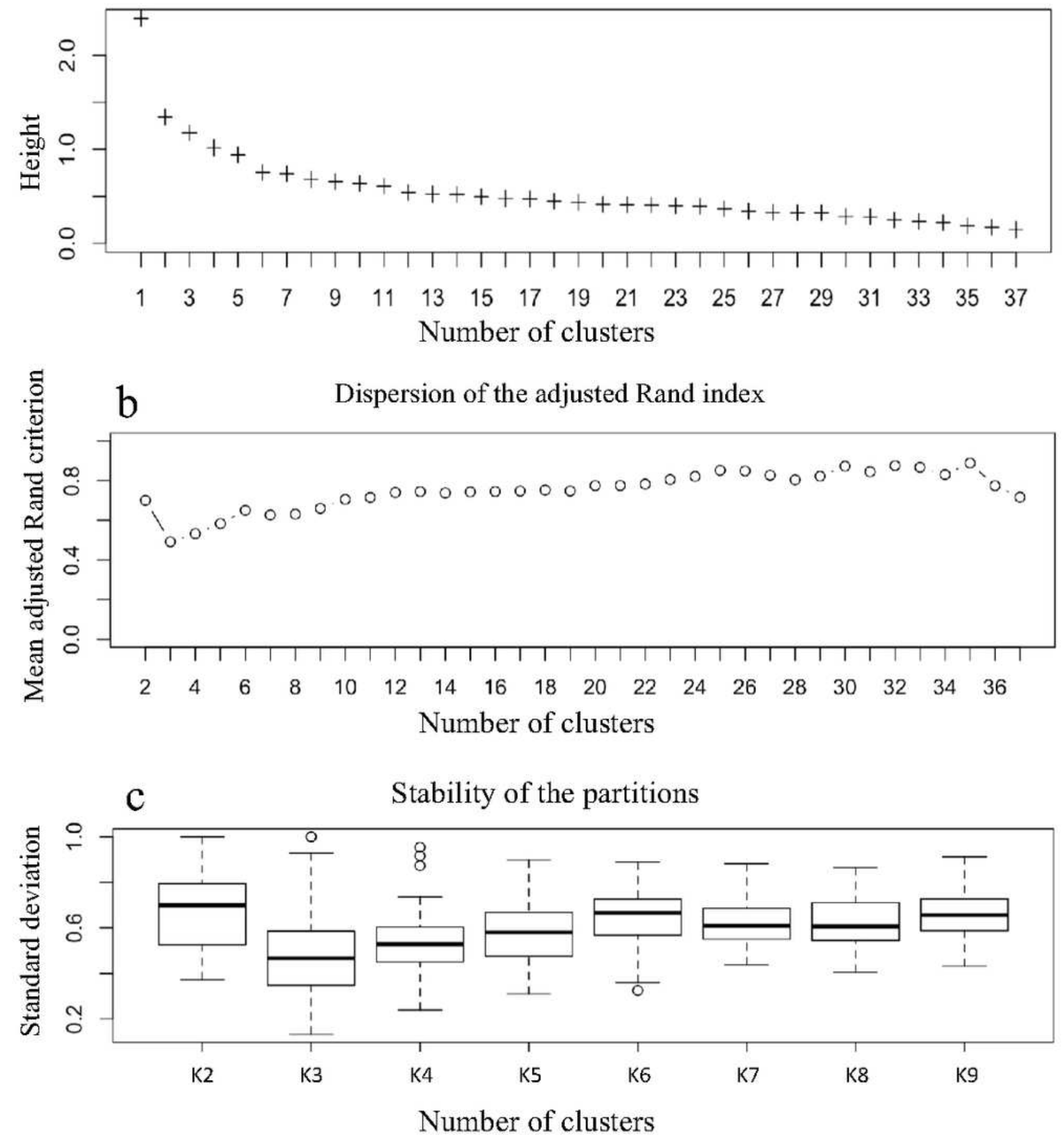

Figure 4 
Graphic outputs for cluster decision 4a. Plot of the aggregation levels of symptom clusters 4b. Plot of stability of the partitions of clusters 4c. Plot of dispersion of the adjusted Rand index

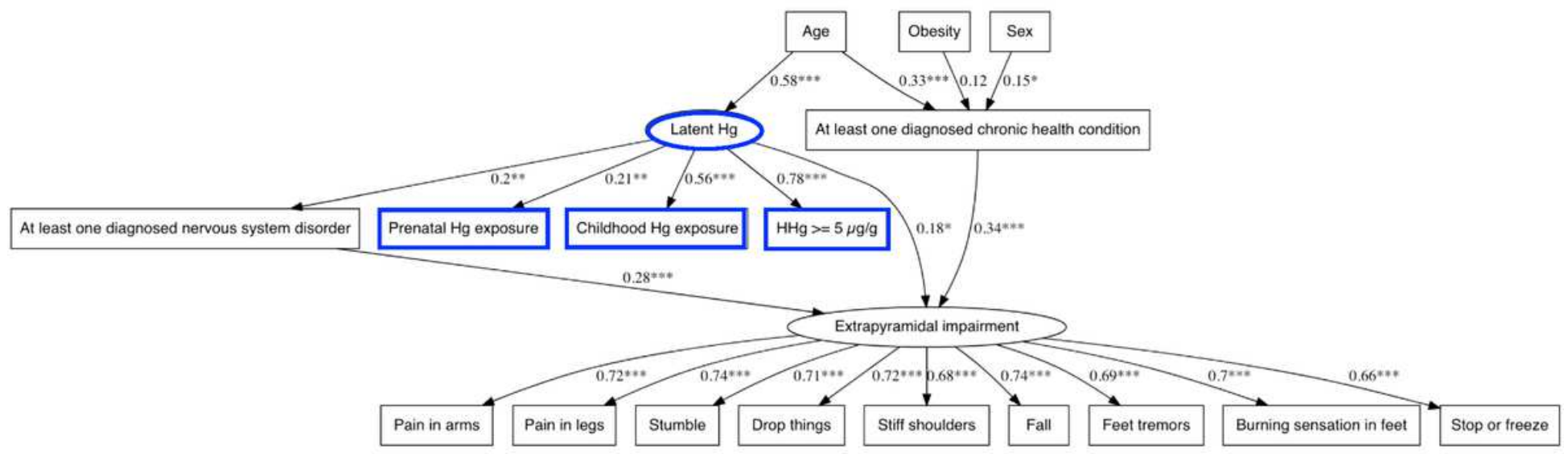

Goodness of fit: $\chi 2 / \mathrm{df}=2.02, \mathrm{CFI}=0.92, \mathrm{TLI}=0.91, \mathrm{RMSEA}=0.06(0.05-0.08), \mathrm{SRMR}=0.06$

Figure 5

SEM path diagram linking retrospective latent $\mathrm{Hg}$ exposure and covariates to the latent symptoms cluster variable for Extrapyramidal impairment.

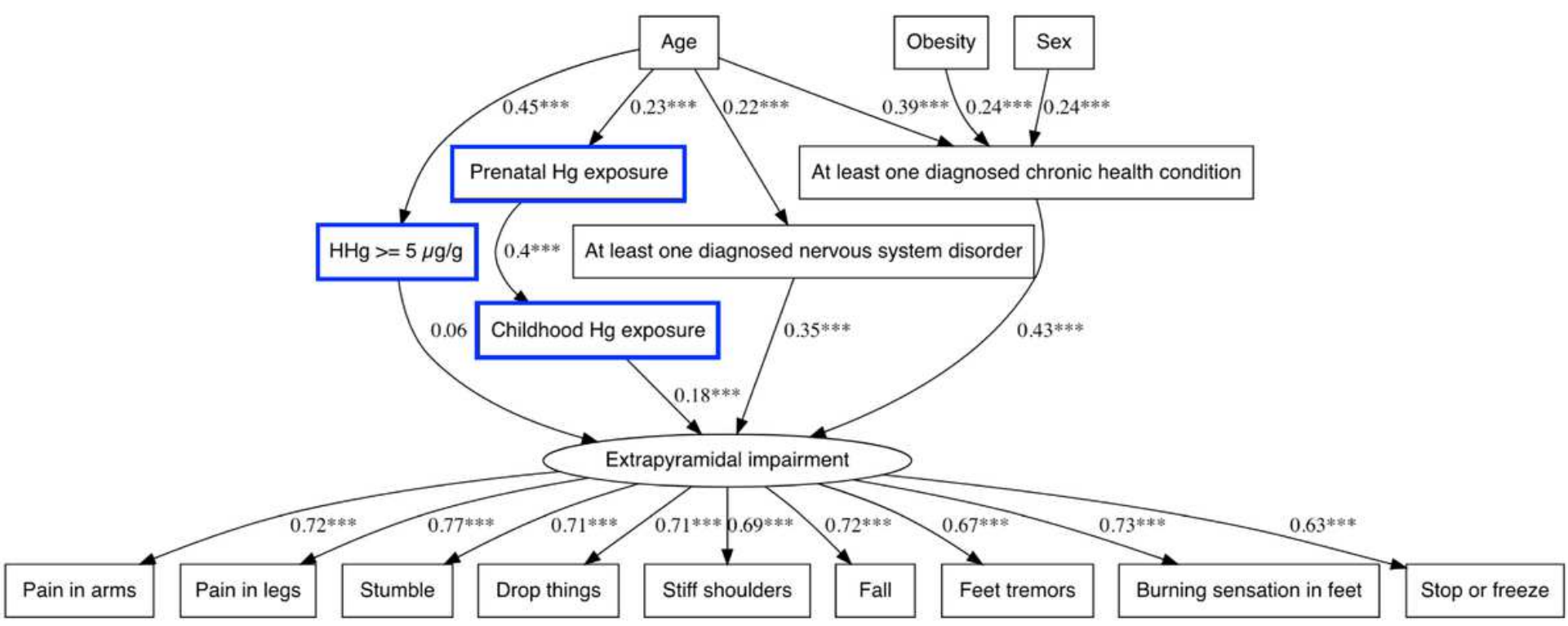

Goodness of fit: $\chi 2 / \mathrm{df}=1.30, \mathrm{CFI}=0.99, \mathrm{TLI}=0.98, \mathrm{RMSEA}=0.03(0.01-0.05), \mathrm{SRMR}=0.06$

Figure 6

SEM path diagram linking retrospective $\mathrm{Hg}$ exposure parameters (prenatal and childhood $\mathrm{Hg}$ exposure, and having had $\geq 5 \mu \mathrm{g} / \mathrm{g}$ hair $\mathrm{Hg}$ at least once between 1970 and 1997) and covariates to the latent symptoms cluster variable for Extrapyramidal impairment. 

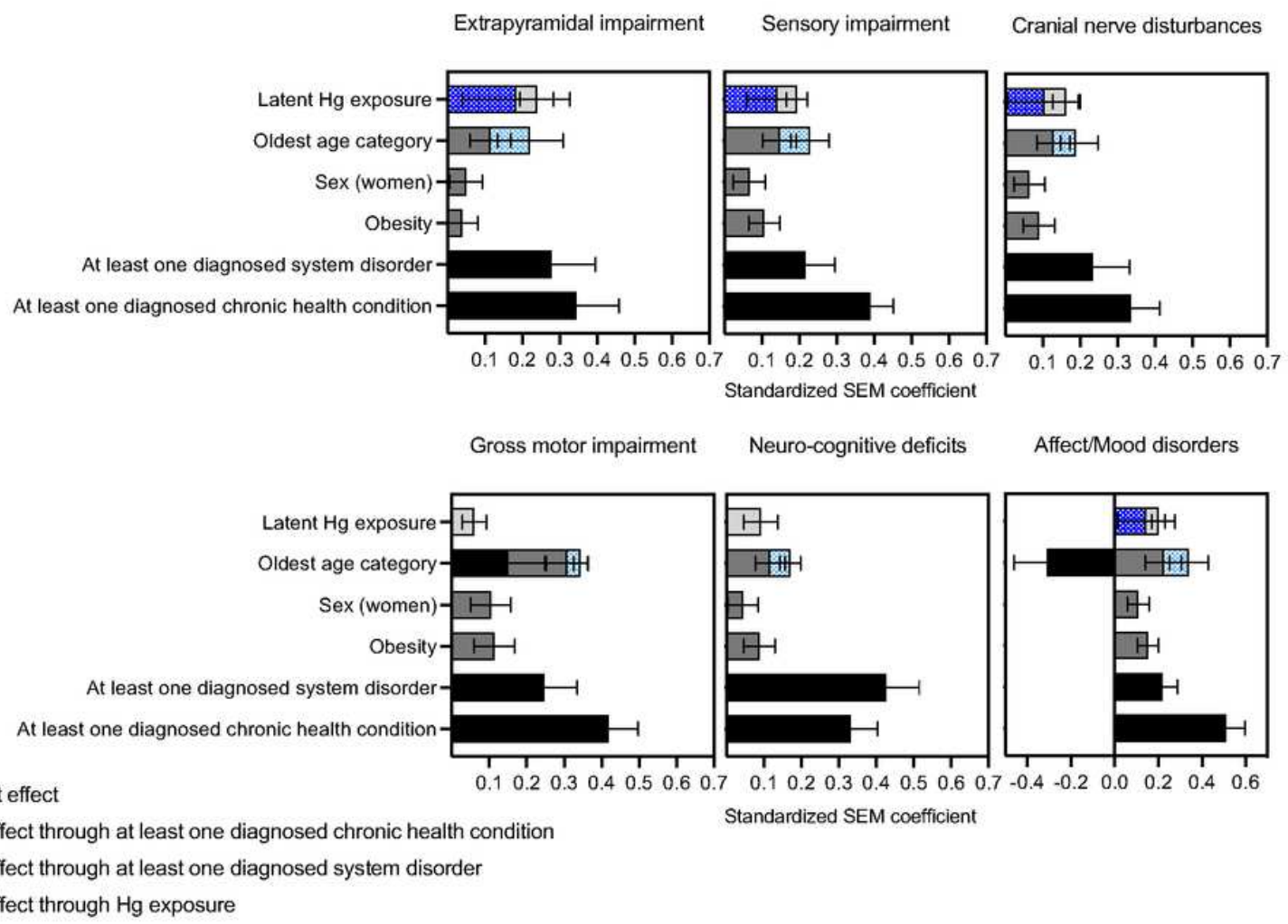

\section{Figure 7}

\section{SEM standardized path coefficients for direct and indirect contributions of latent $\mathrm{Hg}$ and covariates on} the symptom latent variable for each cluster

\section{Extrapyramidal impairment Sensory impairment Cranial nerve disturbances}
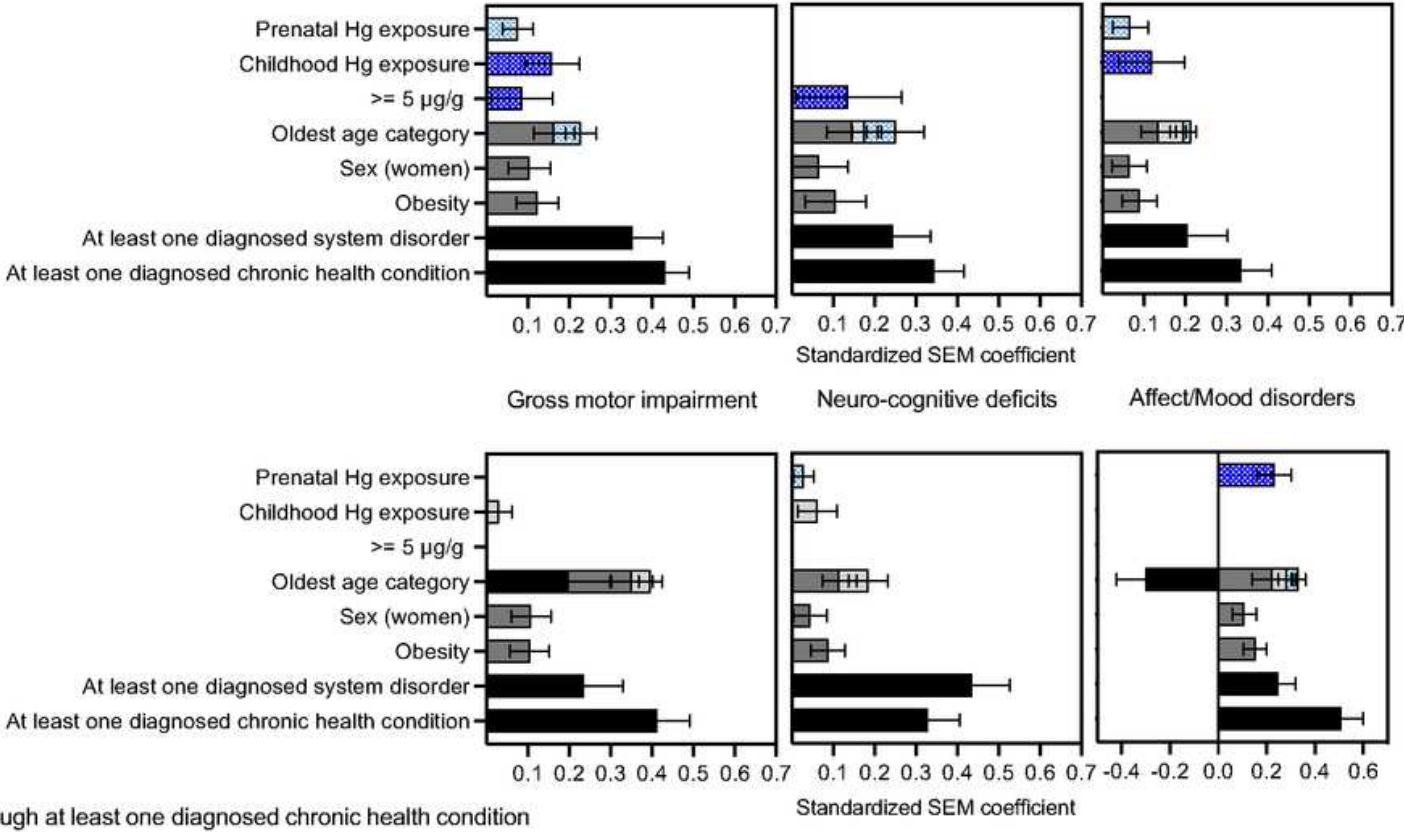

$\square$ Indirect effect through at least one diagnosed chronic health condition

Standardized SEM coefficient

$\square$ Indirect effect through at least one diagnosed system disorder

$\square$ Indirect effect through $\mathrm{Hg}$ exposure 
Figure 8

SEM standardized path coefficients for direct and indirect contributions of prenatal, childhood and $\geq$ $5 \mu \mathrm{g} / \mathrm{g}$ hair $\mathrm{Hg}(1970$ - 1997) and covariates on the symptom latent variable for each cluster

\section{Supplementary Files}

This is a list of supplementary files associated with this preprint. Click to download.

- Additionalfile1ENHED2100280.pdf 